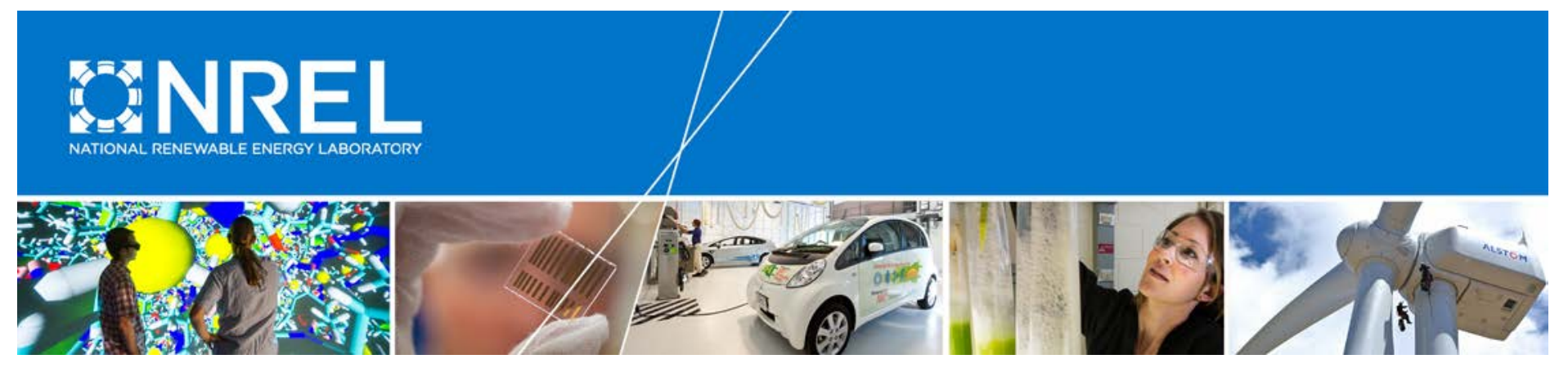

\title{
Final Technical Report: Integrated Distribution- Transmission Analysis for Very High Penetration Solar PV
}

Bryan Palmintier, Elaine Hale, Timothy M. Hansen, Wesley Jones, David Biagioni, Kyri Baker, Hongyu Wu, Julieta Giraldez, Harry Sorensen, Monte Lunacek, Noel Merket, Jennie Jorgenson, and Bri-Mathias Hodge National Renewable Energy Laboratory

NREL is a national laboratory of the U.S. Department of Energy Office of Energy Efficiency \& Renewable Energy Operated by the Alliance for Sustainable Energy, LLC

This report is available at no cost from the National Renewable Energy Laboratory (NREL) at www.nrel.gov/publications.

Technical Report

NREL/TP-5D00-65550

January 2016 


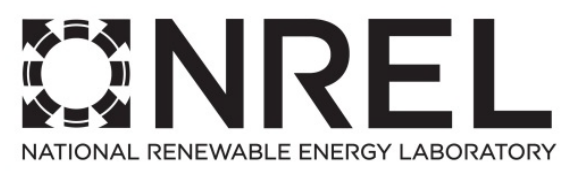

\section{Final Technical Report: Integrated Distribution- Transmission Analysis for Very High Penetration Solar PV}

Bryan Palmintier, Elaine Hale, Timothy M. Hansen, Wesley Jones, David Biagioni, Kyri Baker, Hongyu Wu, Julieta Giraldez, Harry Sorensen, Monte Lunacek, Noel Merket, Jennie Jorgenson, and Bri-Mathias Hodge National Renewable Energy Laboratory

Prepared under Task No. SS13.9501 and DOE Award No. DE-EE00029075

NREL is a national laboratory of the U.S. Department of Energy Office of Energy Efficiency \& Renewable Energy Operated by the Alliance for Sustainable Energy, LLC

This report is available at no cost from the National Renewable Energy Laboratory (NREL) at www.nrel.gov/publications.

National Renewable Energy Laboratory 15013 Denver West Parkway Golden, CO 80401 303-275-3000 • www.nrel.gov
Technical Report

NREL/TP-5D00-65550

January 2016

Contract No. DE-AC36-08G028308 


\section{NOTICE}

This report was prepared as an account of work sponsored by an agency of the United States government. Neither the United States government nor any agency thereof, nor any of their employees, makes any warranty, express or implied, or assumes any legal liability or responsibility for the accuracy, completeness, or usefulness of any information, apparatus, product, or process disclosed, or represents that its use would not infringe privately owned rights. Reference herein to any specific commercial product, process, or service by trade name, trademark, manufacturer, or otherwise does not necessarily constitute or imply its endorsement, recommendation, or favoring by the United States government or any agency thereof. The views and opinions of authors expressed herein do not necessarily state or reflect those of the United States government or any agency thereof.

This report is available at no cost from the National Renewable Energy Laboratory (NREL) at www.nrel.gov/publications.

Available electronically at SciTech Connect http:/www.osti.gov/scitech

Available for a processing fee to U.S. Department of Energy and its contractors, in paper, from:

U.S. Department of Energy

Office of Scientific and Technical Information

P.O. Box 62

Oak Ridge, TN 37831-0062

OSTI http://www.osti.gov

Phone: 865.576.8401

Fax: 865.576.5728

Email: reports@osti.gov

Available for sale to the public, in paper, from:

U.S. Department of Commerce

National Technical Information Service

5301 Shawnee Road

Alexandria, VA 22312

NTIS http://www.ntis.gov

Phone: 800.553 .6847 or 703.605 .6000

Fax: 703.605.6900

Email: orders@ntis.gov 


\section{Executive Summary}

Transmission and distribution simulations have historically been conducted separately, echoing their division in grid operations and planning while avoiding inherent computational challenges. Today, however, rapid growth in distributed energy resources (DERs) - including distributed generation from solar photovoltaics (DGPV) - requires understanding the unprecedented interactions between distribution and transmission. To capture these interactions, especially for high-penetration DGPV scenarios, this research project developed a first-of-its-kind, large-scale, high-performance computer (HPC) based, integrated transmission-distribution tool, the Integrated Grid Modeling System (IGMS). The tool was then used in initial explorations of system-wide operational interactions of high-penetration DGPV. Specifically, IGMS provides:

- A parallel, modular co-simulation framework well suited for HPC architectures;

- Tools to automate large-scale scenario generation, import transmission and distribution models from other formats, and visualize the results;

- Wholesale market simulation with multiple unit commitment and dispatch cycles, as well as Automatic Generation Control (AGC)-based reserve deployment; and

- Simultaneous simulation of a full-scale transmission system (hundreds to thousands of buses) in conjunction with hundreds to thousands of full-scale distribution systems (each with thousands of nodes).

IGMS integrates multiple existing open-source tools into its framework: NREL's Flexible Energy Scheduling Tool for Integrating Variable generation (FESTIV) [1] provides wholesale market and reserve deployment simulation; bulk AC power flow is simulated using MATPOWER [2], and distribution system 3-phase unbalanced AC power flow and physicsbased end-use models are modeled in GridLAB-D [3]. These tools are co-simulated, exchanging information each time step, through the Python and MPI-based IGMS core. This modular framework enables substituting any of these tools and/or adding new tools to enable multidomain analyses. Moreover, the IGMS-suite directly addresses the large data challenges inherent in integrated transmission and distribution simulation through a rich set of automated scenario creation and feeder population tools, data extraction and aggregation capabilities, and input conversion scripts.

IGMS simulations of full-scale transmission and distribution systems ( $>1 \mathrm{M}$ buses) for the project showed how increasing grid operator visibility and forecasting for DGPV can significantly reduce production costs (18\% vs. no awareness) while improving reliability metrics such as CPS2 and statistical measures of area control error (ACE). A case study with advanced inverters providing distribution-level volt/VAR control showed that DGPV can also limit voltage excursions at the transmission level, with minimal effect on reactive power demand. Comparing IGMS to traditional simulations with separate tools highlights the importance of capturing timevarying distribution factors to account for shifting spatial net load patterns during the day.

This research directly addresses two SunShot Systems Integration metrics by (1) helping enable widespread integration of over $100 \%$ peak demand PV on distribution feeders while going beyond existing IEEE and NERC standards and (2) helping PV systems exceed current and future NERC grid performance standards. 


\section{Table of Contents}

Executive Summary ................................................................................................................... iii

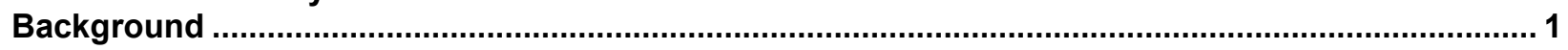

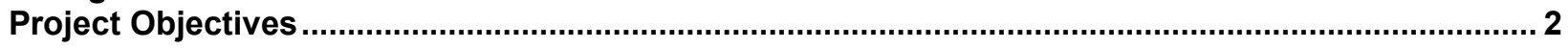

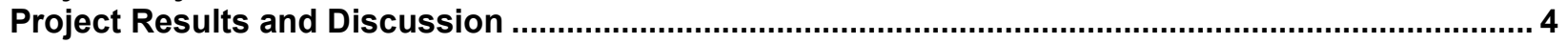

Task 1 - Develop data support modules for IGMS ...................................................................... 4

Subtask 1.1 - Develop IGMS output processing capabilities (and milestone M1A) .................... 4

Subtask 1.2 - Develop semi-automated process to convert system data for IGMS (and milestone

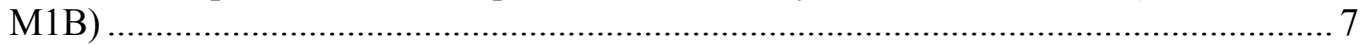

Subtask 2.1: Confirm operation of IGMS model (milestones M2A and M2B) ......................... 9

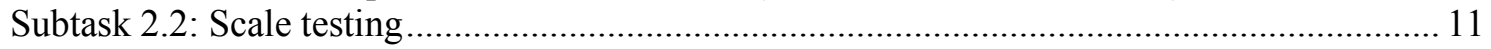

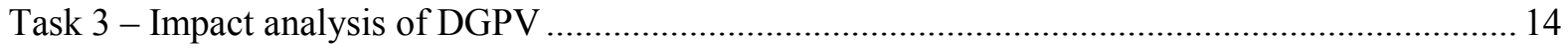

Subtask 3.1 - Define PV scenario parameters and setup simulation....................................... 14

Subtask 3.2 - Explore DGPV reactive power and voltage support for transmission ................... 16

Subtask 3.3 - Explore impact of ISO visibility of DGPV on bulk reserves................................ 18

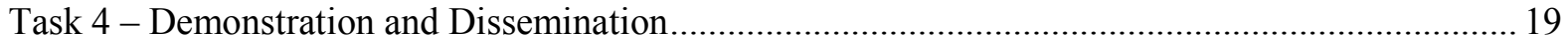

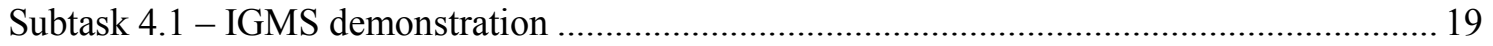

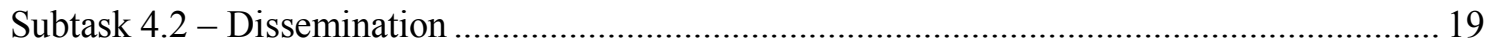

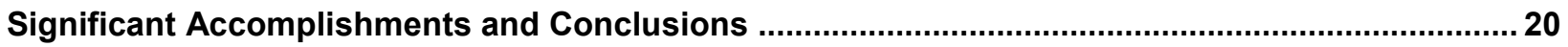

Accomplishment: Full-Scale Integrated Transmission + Distribution Runs............................ 20

Accomplishment: Automated Scenario Creation .............................................................. 21

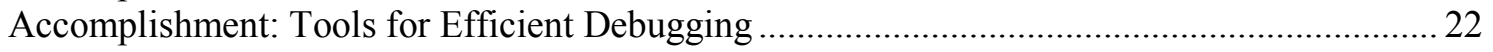

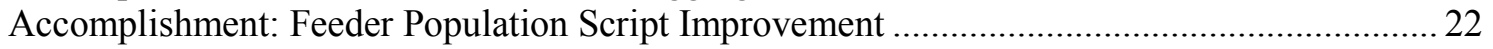

Accomplishment: Parallelization Efforts and Improved GridLAB-D Interfacing ...................... 24

Challenge Overcome: Performance Issues and Balancing Memory Across Ranks ................... 25

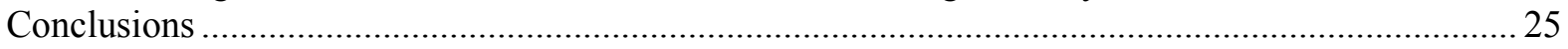

Inventions, Patents, Publications, and Other Results .............................................................. 26

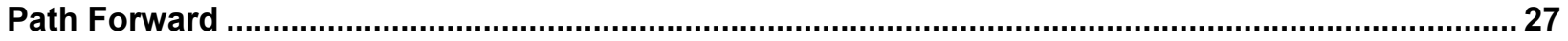

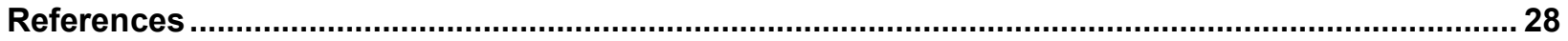

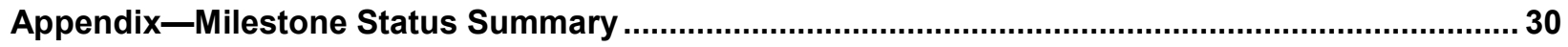




\section{Background}

An increase in renewable penetration, advancements in power electronics and related technologies, and an increase in distributed energy resources (DERs) call for a new class of tools that provide a basis for simulation and analysis of these changing power systems. The traditional boundary between transmission and distribution is no longer well defined, especially with an increase in demand-side generation and intermittent energy sources. Integrated modeling of the entire power system, from the market level down to the load dynamics, can capture these effects by illustrating transmission system influences on distribution and vice versa.

Historically, power systems analysis has been performed using isolated sub-domain tools for transmission (e.g., PSS/E), distribution (e.g., CYMDIST), wholesale market simulation (e.g., PLEXOS), building simulation (e.g., EnergyPlus), and distributed generation (e.g., SAM). While these tools are adequate for analyzing certain aspects of the electric power grid, they tend to greatly simplify other aspects. In recent efforts, work has been done to combine multiple domains into integrated tools. New Power Technologies' transmission impact analysis was performed to analyze distributed photovoltaics [4], in addition to Pacific Northwest National Laboratory (PNNL)'s GridLAB-D [3], which integrates distribution systems, simple end-use models, and basic transactive markets. However, in order to reduce the computational burden of simulating the entire power system, these tools greatly reduce the complexity of the power system models.

One strategy to overcome this and other issues with large-scale simulation is to combine multiple domains through "co-simulation," in which multiple tools interact with each other while running simultaneously [5]-[8]. One example of a co-simulation framework is the Framework for Network Co-Simulation (FNCS). The FNCS provides a co-simulation framework for integrating both power system studies and communication networks [7]. The framework developed in [6] explores the dynamic $(\sim 10 \mathrm{~ms})$ interactions between a single transmission and distribution system. In contrast to these works, which co-simulate a small to moderate number of distribution systems with the transmission system, IGMS is capable of simulating hundreds to thousands of distribution systems in conjunction with transmission, allowing for the analysis of market and transmission-level impacts of DERs.

In [9], [10] further examples of power system co-simulation frameworks are shown. In [9], a cosimulation framework between a multi-agent system (MAS) for smart grid controls and the power systems analysis tool PowerWorld is developed. Additional works on this topic have looked at portions of the power system co-simulated with the communication required for advanced power system controls [11]-[14]. In [15], an integrated transmission-distributioncommunication co-simulation framework is introduced and demonstrated using a small test system. While promising, these past efforts have only been demonstrated on relatively smallscale power systems and typically use highly simplified transmission and market operations.

The IGMS project demonstrates integrated simulation of larger power systems, with hundreds of transmission nodes and over a million $(>1,000,000)$ distribution nodes, and includes a rich representation of bulk power market operations through the Flexible Energy Scheduling Tool for Integration of Variable Generation (FESTIV) [1]. By taking advantage of high-performance computing (HPC) and a scalable architecture, the coupling of hundreds to thousands of 
distribution feeder models with hundreds of transmission buses is achieved. Thus, it becomes possible to simulate hundreds of thousands to millions of individual DERs with great detail, while capturing their interactions and various levels of the system.

\section{Project Objectives}

Meeting the DOE SunShot Initiative goals of reducing installed costs of solar energy by $75 \%$ could result in $20 \%$ of U.S. electricity production from solar, including areas of the power system with greater than $100 \%$ of peak load provided by distributed generation from solar photovoltaic systems (DGPV). However, successfully integrating such very high penetrations of DGPV into the power system will likely only be possible if DGPV no longer acts simply as negative load, but instead becomes an active participant in large-scale electric power system operations. Because considerable PV will likely be installed at the distribution level, realizing this vision will require tearing down the traditional divide between the transmission and distribution systems to first analyze and later implement a truly integrated high-penetration PV future. This transition will require developing new tools that can effectively simulate distribution- and transmission-level interactions.

This project developed such a tool, the Integrated Grid Modeling System (IGMS), which is now up and running for over 1 million transmission and distribution buses and ready to apply toward better understanding future power systems with high penetrations of distributed resources. This year's efforts achieved three primary goals:

1. Developing and refining the IGMS framework and supporting tools so they will be ready to support more extensive follow-on work in partnership with utilities and other stakeholders;

2. Validating the IGMS tool by analyzing results and cross-validation with component models; and

3. Applying IGMS to a few simple motivating questions that begin to illustrate the potential for such a tool. Specifically, this year the project explored two research question(s):

- To what extent can high-penetration DGPV with advanced inverters contribute to bulk system reactive power and voltage support? How does this change with PV penetration?

- Can ISO-level visibility of DGPV reduce required bulk system reserve requirements while maintaining reliability standards? How does this change with PV penetration?

As summarized in Figure 1, these objectives were accomplished through four tasks. These tasks and their outcomes are described in more detail below. 
Project Management Plan for Integrated Distribution-Transmission Analysis for Very High Penetration Solar PV Agreement Number: 29075

PI: Byan Patrintier

National Renewable Energy Laboratory

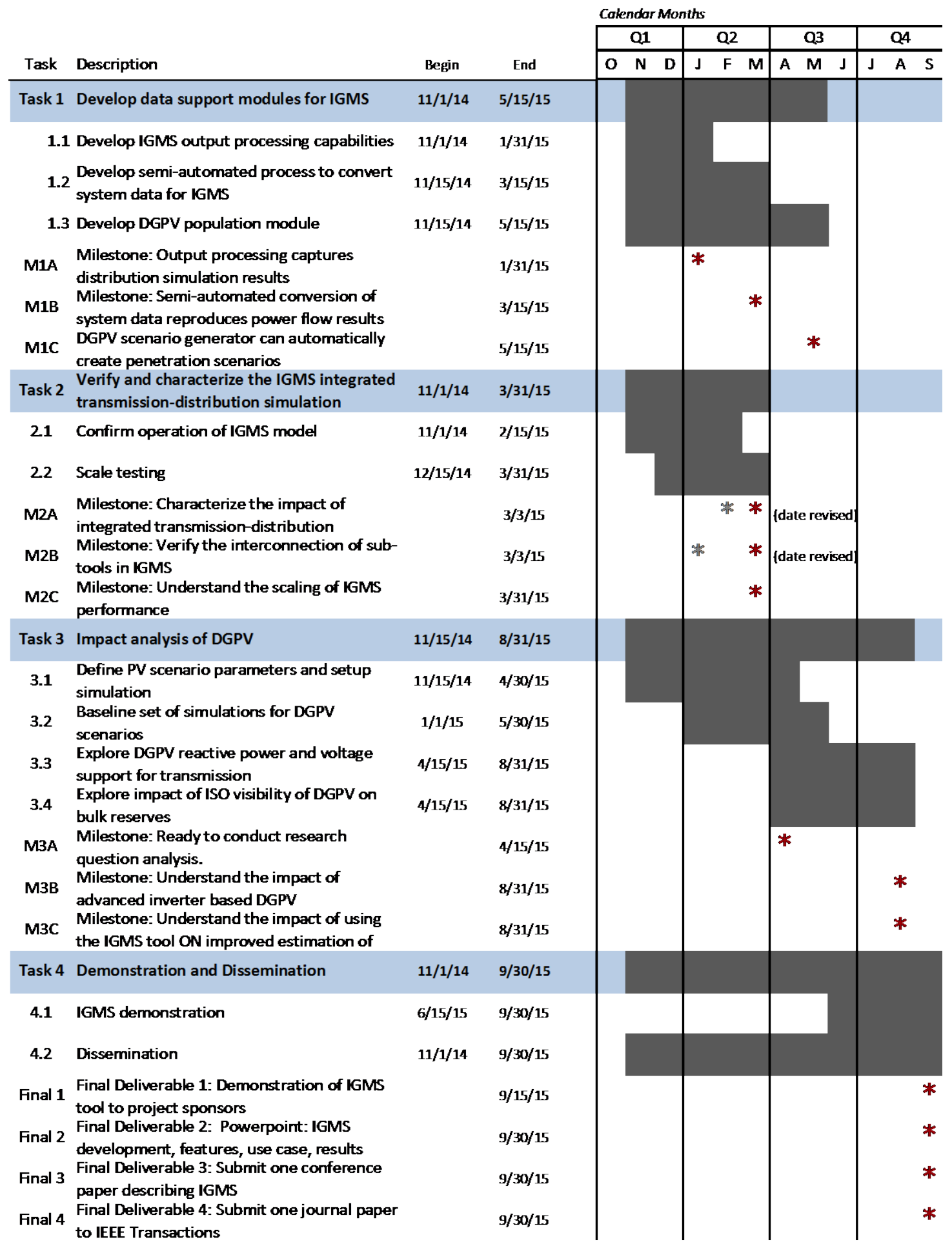

Figure 1. Summary of project tasks, milestones, and deliverables 


\section{Project Results and Discussion}

\section{Task 1 - Develop data support modules for IGMS}

As described in the project-level motivation, successfully integrating very high penetrations of DGPV will require new tools capable of capturing the interactions between the transmission and distribution systems. NREL's pre-project prototype of IGMS could capture these key interactions; however, it required some additional development to achieve its full potential for simulating full-scale real-world power systems. This task developed three key software modules to support IGMS analysis of high-penetration DGPV:

1. Output processing to collect, store, process, and present the large quantity of data generated by a time-series simulation of the IGMS tool,

2. Input processing to begin to enable the automated conversion of utility data to the formats required by IGMS, thereby setting the groundwork for replacing the current use of PNNL taxonomy feeders [16] with utility-specific real world data, and

3. A solar scenario generation module to manage the large quantity of solar resource data and to populate, place, and size DGPV systems in the simulated grid to create possible future scenarios for analysis.

\section{Subtask 1.1 - Develop IGMS output processing capabilities (and milestone M1A)}

The purpose of this task was to enhance user accessibility of the large quantity of data produced by the IGMS when conducting an integrated transmission-distribution simulation.

Every IGMS analysis consists of three steps:

1. Construct the scenario

2. Run the simulation

3. Analyze the results (missing at start of FY15).

The NREL-developed IGMS prototype available at the start of FY15 only covered the first two phases of an IGMS analysis: construction and running. Because of Task 1.1 this third "analysis" stage is now a reality. Specifically, IGMS now supports output processing in three key ways:

- Automated text-based reporting (based on flexible templates)

- Scripted graphics generation (highly customizable)

- A framework for exploratory data analysis.

All three of these provide access to the combination of HDF $5^{1}$ data from the bulk power system (FESTIV and MATPOWER), and the dozens of CSV output files created for each of the hundreds to thousands of instances of distribution simulations (GridLAB-D) in a given IGMS run (thousands to tens of thousands of output files in total). During this task, the NREL team also made a tool for collecting the scattered distribution simulation data into a single HDF5 file.

\footnotetext{
${ }^{1}$ HDF5 or Hierarchical Data Format v5 is an (large data) industry standard data model and software library that is widely supported across platforms and in a wide range of software packages, and supports parallel read/write access.
} 
The majority of this subtask focused on effectively collecting and displaying the distribution time series data because the transmission data are already in a single location. The goal was to verify that our automated analysis tools properly gathered the correct data. In Figure 2 and Figure 3, the left figure shows the automated visualization output and the right shows the tediously constructed manual Excel plot from the original data source. The desired outcome is for the left figure to look like the right. Figure 2 shows matching results for the time series of total demand broken down by feeder. Figure 3 shows matching results for a summary of net demand for all feeders. Rather than cluttering the figure with a confusing array of overlapping lines, this figure provides a statistical summary that includes the minimum/maximum envelope, median values, and inner quartiles.
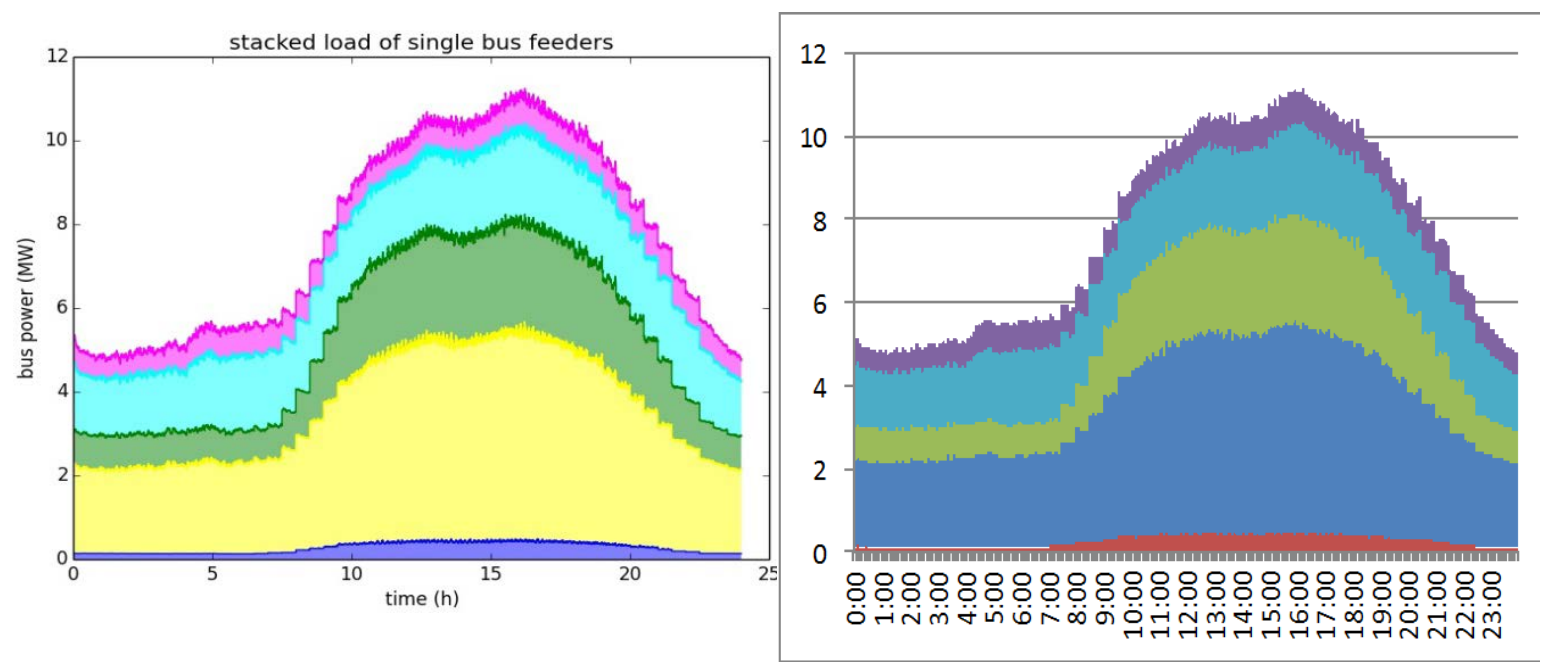

Figure 2. Validation of IGMS automated data extraction and plotting (left) by comparing it with the same plot manually constructed in Excel (right). This type of stacked plot shows the breakdown of total demand by feeder. The transmission equivalent would break down by load bus rather than feeder. 

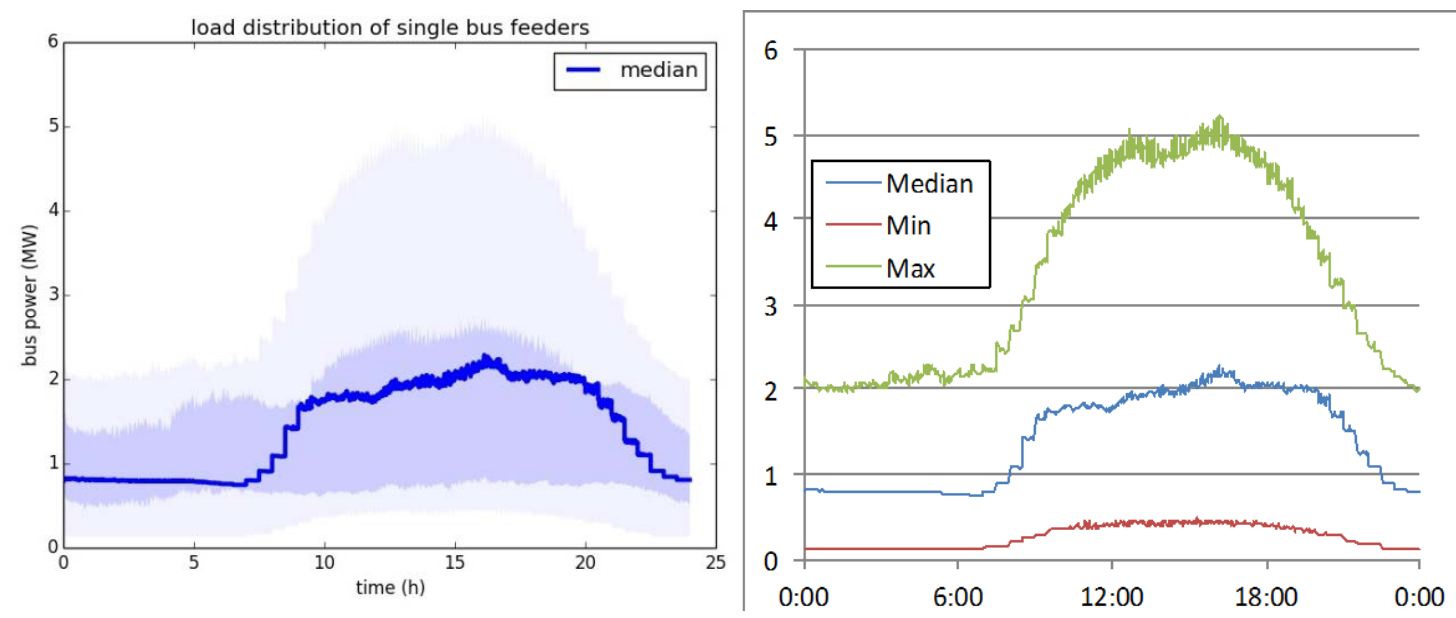

Figure 3. Validation of IGMS Automated data extraction and plotting (left) by comparing it with the same plot manually constructed in Excel (right). This plot is a statistical summary for large number of feeders and nodes in IGMS full-scale analysis and shows the median, $\mathrm{min} / \mathrm{max}$, and inner/outer quartiles. This type of plot is difficult to build in Excel, hence the right figure only shows the three-line equivalent.

Automated tools were also developed for spatial representations of key parameters such as voltage and price (Figure 4). In addition to these automated visuals, this subtask led to the development of:

- A rich set of iPython notebook-based tools for exploratory data analysis by experienced researchers, and

- A flexible, template-based text reporting tool to aid in run confirmation and debugging. This capability overcomes the need for researchers to parse through hundreds or thousands of files to understand what happened during a modeling run, and to begin to understand the results for analysis or the source of challenges for debugging.

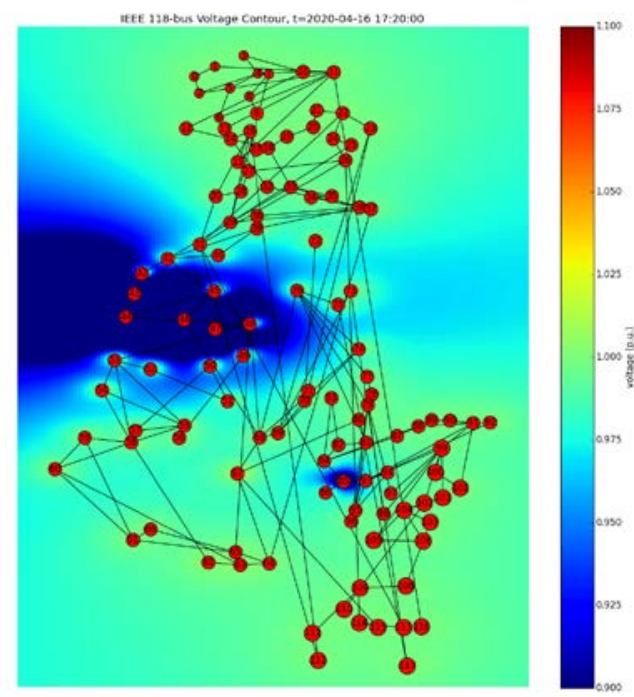

Figure 4. Spatial voltage plot for IEEE-118 bus test run 


\section{Subtask 1.2 - Develop semi-automated process to convert system data for IGMS (and milestone M1B)}

The core goal in this task was to begin to make it easier to use real system data as part of IGMS. To this end, tools and processes were developed to automate the conversion of distribution models available in CYMDIST (part of CYME) and Synergi (previously SynerGEE) to GridLAB-D, and to adapt transmission data available in PLEXOS models for use in FESTIV.

For distribution conversion, a tool was created in Python, and multiple feeders provided by two western U.S. utilities (under NDA with NREL) in SynerGi and CYMDIST format were converted to GridLAB-D format. The conversion was validated by comparing the original results to those produced by the converted GridLAB-D models.

The software is structured such that properties for each Synergi object are collected from the Synergi feeder file in Extensible Markup Language (XML) format, and then operated on via syntax or mathematical conversions to create a corresponding GridLAB-D object. Figure 5 outlines the steps involved on the conversion process.

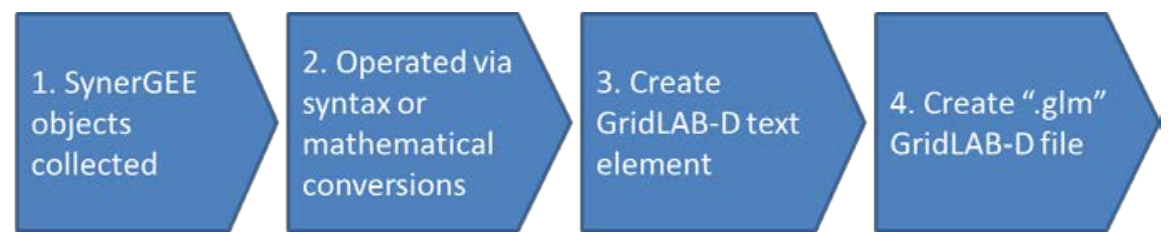

Figure 5. Software structure to convert feeder objects from Synergi to GridLAB-D.

After converting each feeder, the results are validated using a range of metrics:

- Bus voltages $(\mathrm{V})$ for the converted model compared to the bus voltages for the original model should be within acceptable limits (absolute error $<5 \%$ was chosen for this project), and

- The feeder head real $(\mathrm{P})$ and reactive $(\mathrm{Q})$ power compares to the original model within acceptable limits of $<5 \%$.

Since the native model in Synergi does not contain any time series data, the comparisons for this milestone are based on a single "snapshot" powerflow solution at the given (design) point.

A similar tool was developed for CYMDIST using a modular code base.

For transmission conversion, the team evolved an existing PLEXOS-FESTIV conversion tool (written in Python and built on libraries for SQLite database versions of PLEXOS models and FESTIV's Excel spreadsheets) was updated to support both revised data formats and a streamlined dependency set. Data conversion from PLEXOS to FESTIV required the following semi-automated set of steps:

1. (Automated) Convert the PLEXOS XML-format input database to SQLite format using a command line tool from plexos2festiv.

2. (Automated) Convert this SQLite database into a FESTIV input Excel spreadsheet using a second command line tool from plexos2festiv. 
3. (Manual) Adapt time series data to the structure required by FESTIV, notably adding high-resolution AGC-timescale demand data.

4. (Manual) Add pointers to time series data files from the FESTIV system data spreadsheet.

This process was applied to PLEXOS data created from a nodal model of WECC that was downselected to just the SMUD balancing area. (The model is based on the WECC-TEPPC 2020 data, which gives the misnomer of SMUD to the Balancing Authority of Northern California (BANC). This is corrected in the latest TEPPC database.) To verify successful conversion, the SMUD model was run in both PLEXOS and FESTIV for one simulated day $(4 / 16 / 2020)$ and the results were compared.

As seen in Figure 6, the total generation generally compares well between PLEXOS and FESTIV. Here the variations among the different FESTIV configurations are clearly visible. The apparently missing generation is provided by interchanges. Three types of discrepancies exist:

- A time series shift of 1 hour visible as a vertical line at 1:00. This shift was corrected for subsequent runs.

- Some variation (small offset, wiggles) among the time series data resulting from slight differences in solver solutions where interchange can sometimes result in similar convergence levels for somewhat different solutions; and

- A commitment challenge for the PLEXOS model around 21:00 that results in the largest errors for all FESTIV time series results.

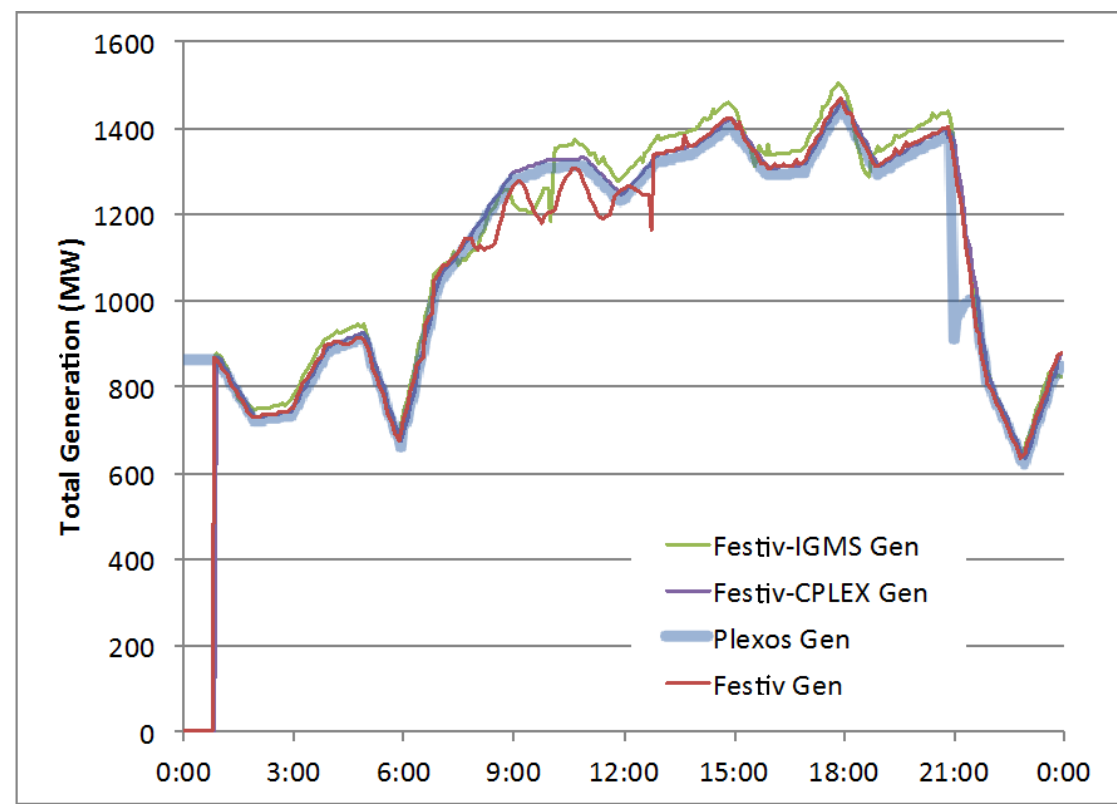

Figure 6. Time series comparison for total load between PLEXOS and multiple FESTIV runs 


\section{Task 2 - Verify and characterize the IGMS integrated transmission-distribution simulation}

Task 2 included two milestones related to testing the analytical and computational performance of IGMS. One compared the integrated operation of IGMS to the same tools running separately. The other quantified the computational performance of IGMS, which revealed the unexpected result that while the separate tools (FESTIV and GridLAB-D) both run quickly, the integrated IGMS tool produced a larger-than-expected slowdown. In subsequent work, we were able to revisit and address this performance gap, the results of which are highlighted below.

\section{Subtask 2.1: Confirm operation of IGMS model (milestones M2A and M2B)}

This subtask involved two interrelated comparisons (captured as milestones M2A and M2B) that both involved running the IGMS tool suite multiple times to compare the impacts of coupled transmission and distribution vs. separate analysis.

To complete these comparisons, a total of five simulations were run:

1. “GridLAB-D (pre)": GridLAB-D stand-alone with transmission as a "perfect" nominal voltage source;

2. "FESTIV (pre)": FESTIV/MATPOWER stand-alone using the aggregated results of the GridLAB-D (pre) run to provide a very accurate load forecast for day-ahead and hourahead commitment decisions;

3. "IGMS": A fully integrated run with GridLAB-D interacting with FESTIV and MATPOWER at each 1-minute timestep;

4. “GridLAB-D (post)": GridLAB-D stand-alone with bus-by-bus voltage recorded from the IGMS run and passed into GridLAB-D as exogenous input; and

5. “FESTIV (post)": FESTIV/MATPOWER run standalone using aggregated demand data drawn from the IGMS integrated run.

This results in four pairwise comparisons with IGMS:

1. GridLAB-D (pre) to IGMS

2. FESTIV (pre) to IGMS

3. IGMS to GridLAB-D (post)

4. IGMS to FESTIV (post).

All analyses for this subtask were conducted using the IEEE 118 bus transmission system with loads populated as a mix of $20 \%$ full GridLAB-D simulation (a total of 131 feeders) and $80 \%$ "file buses" that read input data from a file containing a time series of pre-computed loads. The simulations were all run for one simulated shoulder season weekday in 2020: Thursday, April $16^{\text {th }}, 2020$. Distribution data were taken from the PNNL taxonomy feeders [16] and assigned to transmission buses so as to match estimated peak load. The distribution system was populated with a baseline set of technologies and $0 \%$ solar penetration. 
To ensure a reasonable comparison, the FESTIV total demand and distribution factors for the integrated IGMS and FESTIV-alone (pre) were taken from the Gridlab-D standalone run. Something like this was needed to ensure the unit commitment and dispatch decisions are reasonable; however, using the GridLAB-D data for this effectively assumes a near-perfect forecast which will reduce the differences during in the comparisons measured here for the milestone. Going forward the IGMS team is looking in to simple ways to develop more realistic synthetic forecasts and improve the realism of future scenarios. Until this is in place, the analyses presented here may underestimate the value of integrated simulation.

Results from this comparison are summarized in Table I. The differences between runs was computed using the mean relative difference:

$$
\mathrm{MRD}=E\left(\left|\frac{v_{1}-v_{2}}{v_{1}}\right|\right)
$$

Where $\mathrm{E}()$ is the expectation operator, also known as the mean, or average; and $v_{1}$ and $v_{2}$ are the two values being compared. Table I shows the MRD between these simulations for real power $(|\Delta \mathrm{P}|)$, reactive power $(|\Delta \mathrm{Q}|)$, and voltage $(|\Delta \mathrm{V}|)$. In all but one case, the "pre" results have larger differences than the "post" results. This suggests the importance of capturing integrated transmission and distribution simulations. The only exception to this trend was in transmissionlevel (using FESTIV) voltage, where the differences were slightly higher for "post;" however the differences for both "pre" and "post" were low enough $(\leq 0.05 \%)$ that this was mostly caused by small random variations. The "post" comparisons show smaller differences in most cases indicating that during the integrated IGMS simulations, data is being exchanged accurately.

Table I. Mean Relative Difference Between Integrated IGMS Transmission-Distribution Simulation vs. Separate Simulations

\begin{tabular}{lccc}
\hline Pairwise comparison & $|\Delta \mathbf{P}|$ & $|\Delta \mathbf{Q}|$ & $|\Delta \mathbf{V}|$ \\
\hline $\begin{array}{l}\text { Comparisons using separate simulations with standard inputs. Larger differences show } \\
\text { importance of running integrated solutions: }\end{array}$ & $13.0 \%$ & $16.3 \%$ & $1.23 \%$ \\
GridLAB-D (pre) to IGMS & $15.8 \%$ & $76.7 \%$ & $0.04 \%$ \\
FESTIV (pre) to IGMS & $0.6 \%$ & $11.1 \%$ & $0.00 \%$ \\
Comparisons using separate simulations with inputs derived from the results of integrated IGMS \\
simulations. Smaller differences illustrate that the integrated tool exchanges data as expected: \\
IGMS to GridLAB-D (post) & $11.5 \%$ & $22.0 \%$ & $0.05 \%$ \\
IGMS to FESTIV (post). & & & \\
\hline
\end{tabular}

However, the real and reactive power differences in both "pre" and "post" were surprisingly high. Some of these load differences can be attributed to voltage differences, which tend to proportionately impact loads - a phenomina exploited by conservation voltage reduction (CVR) at the distribution level. However, the small $(<1.5 \%)$ voltage differences are not enough alone to explain the $10+\%$ load differences. Instead, further analysis reveals that the major differences in loads for both "pre" and "post" comparisons are due to the transmission stand-alone simulation assumption of constant load distribution factors. This assumption means that the total demand profile for the entire service area is always distributed in the same way independent of 
the time-of-day. Such an assumption is common practice not only for modeling, but also for Independent System Operator (ISO) and utility operations.

In reality, however, the demand pattern will vary throughout the day as portions of the distribution system have relatively higher or lower demands during certain hours. For instance, largely residential feeders will typically have higher demands on weekday mornings and evenings, while commercial feeders normally peak during business hours. As seen in Figure 7, the IGMS integrated simulation captures these time varying differences. In this figure the constant distribution factors used in transmission-only simulation (Figure 7(a)) appear as uniform horizontal bars across all time periods, while the more realistic time varying load distribution captured with IGMS (Figure 7(b)) is clearly seen as variable widths in the relative contribution of load buses to the total demand.

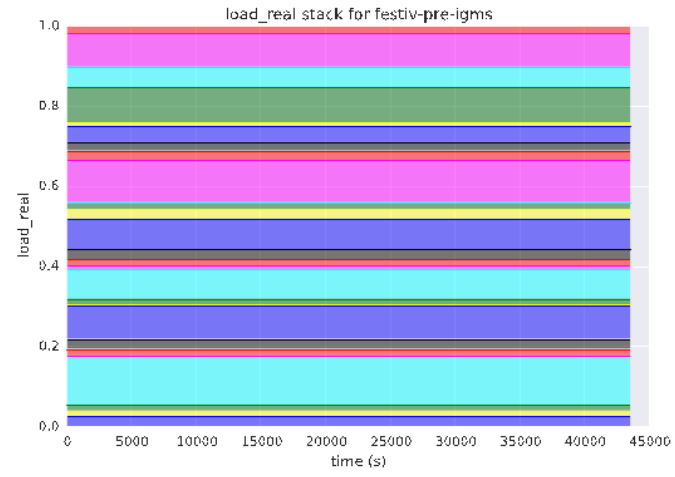

(a)

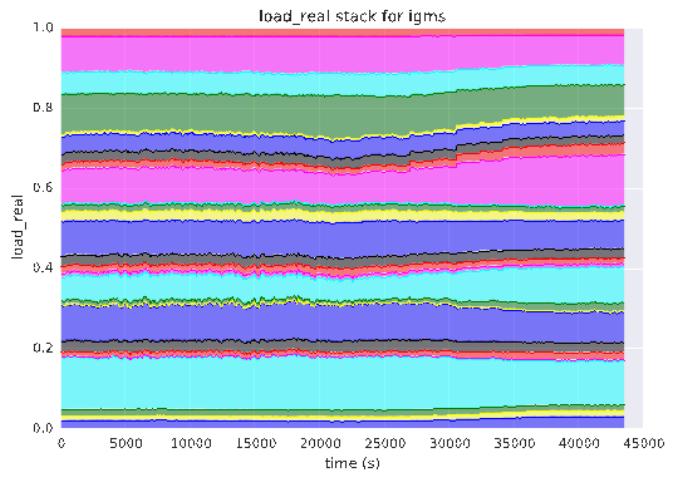

(b)

Figure 7: Comparison of normalized stacked load charts for traditional transmission only (FESTIVpre) simulation (a) and integrated T+D simulation with IGMS (b)

Hence much of the power errors seen in the table above () can be traced to the assumption of constant distribution factors by the transmission-only (FESTIV) simulation. This also suggests that separate transmission simulations could be substantially improved by introducing time varying load distribution factors.

Finally, this subtask also led to important improvements in the IGMS tool. The deep data introspection required for these milestones revealed a series of subtle bugs that are now fixed, and resulted in additional automated data collection and debugging infrastructure.

\section{Subtask 2.2: Scale testing}

This subtask explored how the performance of IGMS scales as a function of the scale of the problem and the amount of computational resources used. To better understand the scaling of IGMS, we developed a wide range of scenarios varying the bulk system size, number of distribution feeders, type of load model, and computing resources available to solve the problem. For each underlying model (choice of transmission system) the following steps were conducted:

1. Build the bulk power system data in FESTIV/MATPOWER (only required for the new 14 bus system). 
2. Populate the $100 \%$ feeder case using the IGMS scenario construction scripts, which optimize the placement of available feeders (PNNL taxonomy feeders [16] used in this analysis) to best match distribution peak load to transmission peak load under a number of constraints.

3. Run the baseline GridLAB-D only cases to develop (nearly perfect) baseline load forecasts.

4. Develop revised FESTIV input load data based on the GridLAB-D runs.

5. Create down-selected feeder cases with $<100 \%$ feeders in GridLAB-D. Additional buses are modeled using aggregated time series input data taken from the FESTIV input data.

6. Finally, submit and run all jobs with appropriate computational resources.

During early simulations the team discovered that a key limitation to IGMS scalability is the memory usage of GridLAB-D. In practice each GridLAB-D instance requires approximately 1GB of RAM. To ensure maximum performance, the HPC nodes on Peregrine do not utilize swap files - i.e., they don't write extra RAM demand to the hard disk. Hence, with one feeder per GridLAB-D instance, memory establishes a lower bound on the RAM required to run each scenario. Most nodes on Peregrine have 32 GB (as of 2015) and therefore all of the medium to large IGMS runs require moderately large numbers of nodes, for memory reasons alone. Peregrine also has a few nodes with $256 \mathrm{~GB}$ of RAM that were used during scale testing to understand the impact of limiting the number of nodes/cores available for computation.

All simulations are for one 24-hour period and include:

- Day-ahead security constrained unit commitment (DASCUC),

- Real-time security constrained intra-daily unit commitment (RTSCUC) every 1 hour,

- Real-time security constrained economic dispatch (RTSED) every 5 minutes,

- AGC-based generator control with signals every 1 minute, and

- Distribution system simulation with a minimum 6-second timestep.

In order to characterize IGMS performance as a function of problem size and resources, multiple simulations were performed. Specifically, we first conducted a detailed look at how performance scales as a function of the number of parallel processes made available to the IGMS-core. This parameter is configured in MPI as the number of "ranks." Each rank corresponds to a communication channel between the master (transmission) process and the sub-tier processes (distribution). A simplified description is that MPI separates the vector of transmission data into pieces so that each rank operates on roughly the same portion of the problem.

Usually a rank would be matched to a computation node such that increasing the ranks increases the amount of compute power used to solve the problem. However, since the IGMS's core subtier end is associated with a bus.py and bus.py typically spawns multiple GridLAB-D instances, the number of cores used by the problem is actually determined by the operating system, based on the number of compute nodes and the count of cores per node. 
Ideally with parallel processing, the solution time decreases linearly with the number of ranks, but typically as the number of ranks increases the combination of non-parallel code and communication overhead causes performance causes the speed up to roll off to a less than linear rate, or even for more ranks to decrease performance.

Figure 8 shows both of these phenomena for IGMS with the computational results from simulating the 14-bus system with an increasing number of MPI ranks.

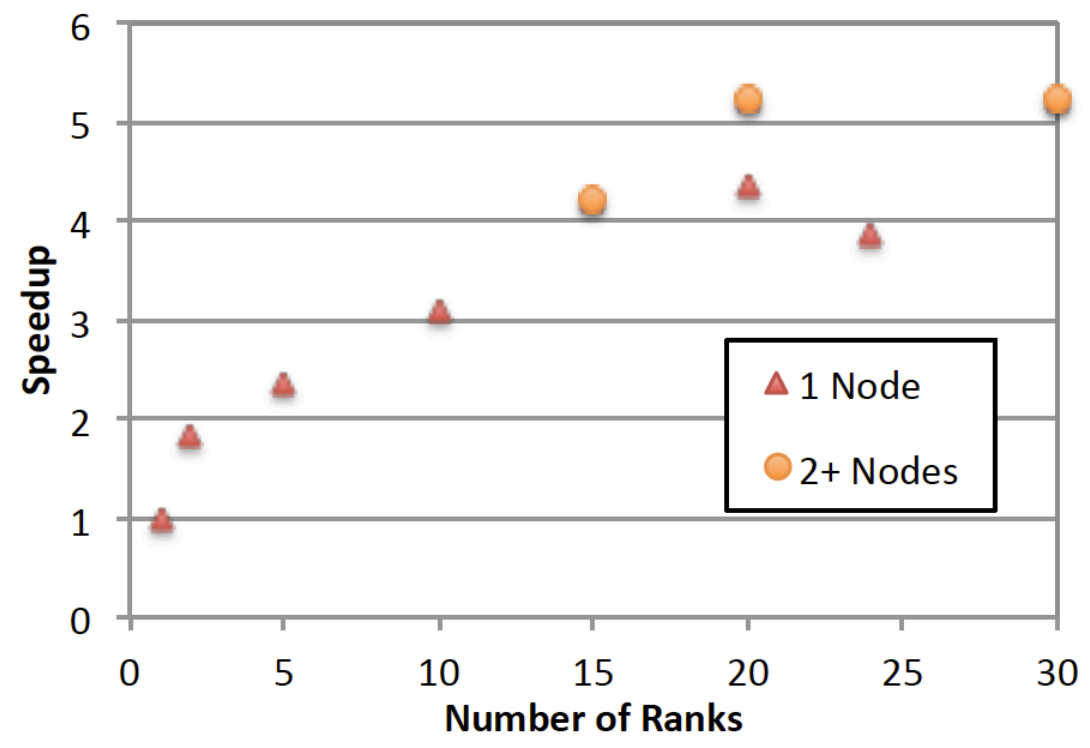

Figure 8. Parallel scaling for the 14-bus test case

As shown in Figure 8, after about four ranks, the linear speedup begins to decrease due to the serial code run times overshadowing the parallelization of the distribution simulations. The figure also shows the importance of ensuring enough computation cores are available with higher MPI-ranks. When only one 24-core node is available, performance suffers beyond about 15 cores. However, when additional cores are made available from an additional node, the operating system is able to effectively parallelize the GridLAB-D runs and improve performance for 20 ranks.

Our second scale test looked at the performance of IGMS as a function of problem size. In this testing, we optimized the number of ranks and nodes/cores available for each problem. Table II shows the simulation times for additional transmission cases: the IEEE 118 bus test case and the SMUD-inspired test case. The run times, increasing with respect to system size, are compared for FESTIV-only simulations versus those using the entire integrated system IGMS. In addition, the total run times for each case become increasingly dominated by the transmission-level simulations at larger sizes. 
Table II. Simulation times and scenario sizes for various transmission cases

\begin{tabular}{rrrrrrrrr} 
& Trans. & \multicolumn{2}{c}{ Distribution } & & \multicolumn{2}{c}{ Run Time (sec) } & \\
\cline { 3 - 4 } System & Nodes & Feeders & Buses & Customers & FESTIV & IGMS & Factor \\
\hline \hline 14-bus & 14 & 30 & 41,077 & 11,019 & & 5,043 & \\
IEEE 118 & 118 & 717 & $1,041,531$ & 241,505 & 4,651 & 15,483 & 3.33 \\
SMUD & 253 & 950 & $1,392,418$ & 322,651 & 21,791 & 46,388 & 2.13
\end{tabular}

\section{Task 3 - Impact analysis of DGPV}

\section{Subtask 3.1 - Define PV scenario parameters and setup simulation}

To perform case studies of the impact of high-penetration distributed PV on system operations, we selected a transmission system roughly based on the Sacramento Municipal Utility District (SMUD). SMUD was chosen as it represents a relatively small but distinct balancing area. This will allow for the examination of a larger number of scenarios within computational limits.

SMUD has a service area that is comprised primarily of Sacramento County California. It is the nation's $6^{\text {th }}$ largest community-owned electric service provider, with a service area population of approximately 1.4 million. The SMUD-like system modeled in IGMS consists of 60 generators, 329 transmission lines, 231 buses, and 83 demand buses. Figure 9 shows a simplified SMUD system topology with simplified single-bus representations of the adjacent PG\&E Valley and TIDC balancing areas.

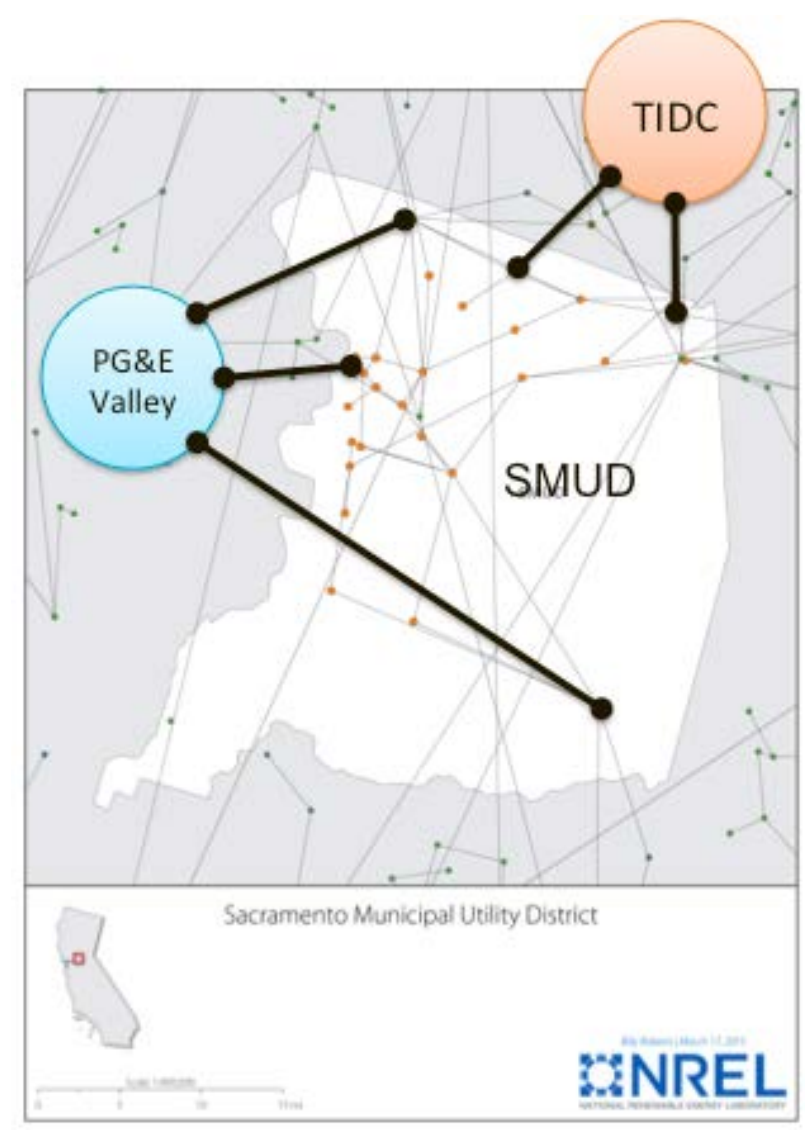

Figure 9. The simplified SMUD system topology with adjacent balancing areas 
Three base cases have been developed, as shown in Table III, that vary in terms of quantity of distributed generation from solar PV (DGPV). Base Case 1 corresponds to a low penetration (BL) roughly equivalent to the current situation where the solar energy produces $2 \%-3 \%$ of annual system energy production. Base Case 2 is a hypothetical mid penetration case (BM) in which the solar energy produces $8 \%-10 \%$ of annual system energy production. Base Case 3 is a high penetration $(\mathrm{BH})$ hypothetical case where the solar energy produces $14 \%-18 \%$ of annual system energy production. In addition to total energy production, all of these scenarios include bus-by-bus and feeder-by-feeder penetration diversity based on DGPV adoption scenarios generated by Solar DS at the zip code level.

At the distribution level, the entire system was emulated in GridLAB-D using 950 feeders assigned (with repetition) from the PNNL taxonomy feeders [16] such that the total load matches that from the 118-bus load levels. These feeders were fully populated with all homes and commercial buildings represented as simple thermal building models with randomized end-use load schedules.

Table III: List of Base Cases

\begin{tabular}{|l|l|}
\hline Case Name & Description \\
\hline Base Case 1 $(\mathrm{BL})$ & $\begin{array}{l}\text { Low solar penetration, 2-3\% of annual system energy } \\
\text { demand }\end{array}$ \\
\hline Base Case 2 $(\mathrm{BM})$ & $\begin{array}{l}\text { Medium solar penetration, 8-10\% of annual system } \\
\text { energy demand }\end{array}$ \\
\hline Base Case 3 $(\mathrm{BH})$ & $\begin{array}{l}\text { High solar penetration, 14\%-18\% of annual system } \\
\text { energy demand }\end{array}$ \\
\hline
\end{tabular}

Impact of DGPV visibility to bulk-power operations

Our initial analysis explored alternative bulk-power operating approaches. Specifically, we setup the following cases:

- No Visibility/No Forecast,

- Persistence forecast for the 5-minute dispatch operations, and

- Perfect forecast using load time series data from running GridLAB-D stand-alone with the same distribution feeders and DGPV systems.

Table IV shows different time settings that will be used in the IGMS simulation, where DASCUC represents day-ahead security constrained unit commitment, RT-SCUC represents realtime security constrained unit commitment, RT-SCED represents real-time security constrained economic dispatch, and AGC denotes the automatic generation control. These timescale settings represent a trade-off between available data granularity and acceptable simulation speed. 
Table IV: Simulation timescales

\begin{tabular}{|c|c|c|}
\hline Module Name & Time Resolution & Scheduling Horizon \\
\hline DA-SCUC & Hourly & $24-36$ hours \\
\hline RT-SCUC & Hourly & $2-4$ hours \\
\hline RT-SCED & $5 \mathrm{~min}$ & 1 hour \\
\hline AGC & $1 \mathrm{~min}$ & -- \\
\hline GridLAB-D & $6-30 \mathrm{sec}$ & -- \\
\hline
\end{tabular}

\section{Subtask 3.2 - Explore DGPV reactive power and voltage support for transmission}

This portion of the project explored the voltage and reactive power impacts of DGPV on the transmission system. For this subtask, the IEEE-118 bus transmission test system was simulated over the course of one day, with $100 \%$ of the transmission system represented in GridLAB-D by a load-matched mix of PNNL taxonomy feeders. [16] DGPV was added to the distribution feeders at a $10 \%$ (energy) penetration level with two configurations:

1. Baseline with DGPV traditional inverters that inject pure real power $(\mathrm{PF}=1)$, and

2. An advanced inverter scenario, where all of the baseline DGPV inverters are replaced with advanced inverters that provide volt/VAR control.

Histograms comparing the distributions of transmission-level reactive power loads for these scenarios are shown in Figure 10. Interestingly, there is very little difference between the reactive power demands, despite the fact that volt/VAR control is typically expected to operate in an absorbing VAR mode to mitigate local voltage rise and hence would be expected to increase reactive power demand. Instead, some of the increase in reactive power is supplied from other advanced inverters that inject some VARs when they observe to local low-voltage condition. But a key additional source of reactive power demand comes from distributionconnected switched capacitor banks, which may be increasingly enabled with the increasing VAR demand. 


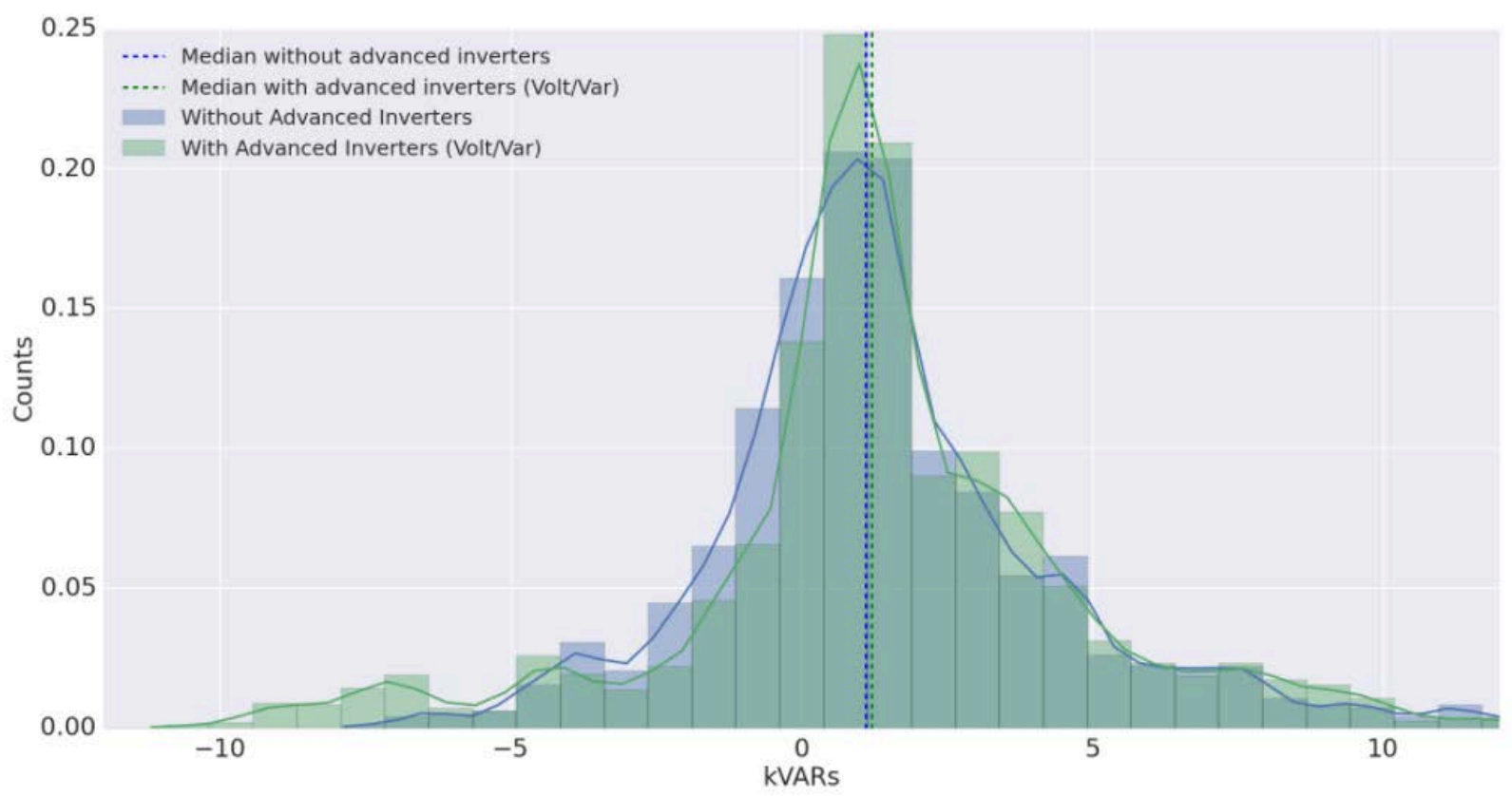

Figure 10. Histograms of transmission bus reactive power flows with and without advanced inverter functionality

In addition, the transmission-level voltage profile when advanced inverters are considered in the system is improved and shifts closer to nominal, as shown in Figure 11 for the voltages at all 118 buses over the course of a 24-hour period. Voltage magnitudes in the transmission system with unity power factor inverters occasionally result in a violation of $+/-5 \%$ of the nominal voltage. Advanced DGPV inverters with volt/VAR control eliminate these violations on the transmission system, as a side effect of regulating the distribution-level voltage. 


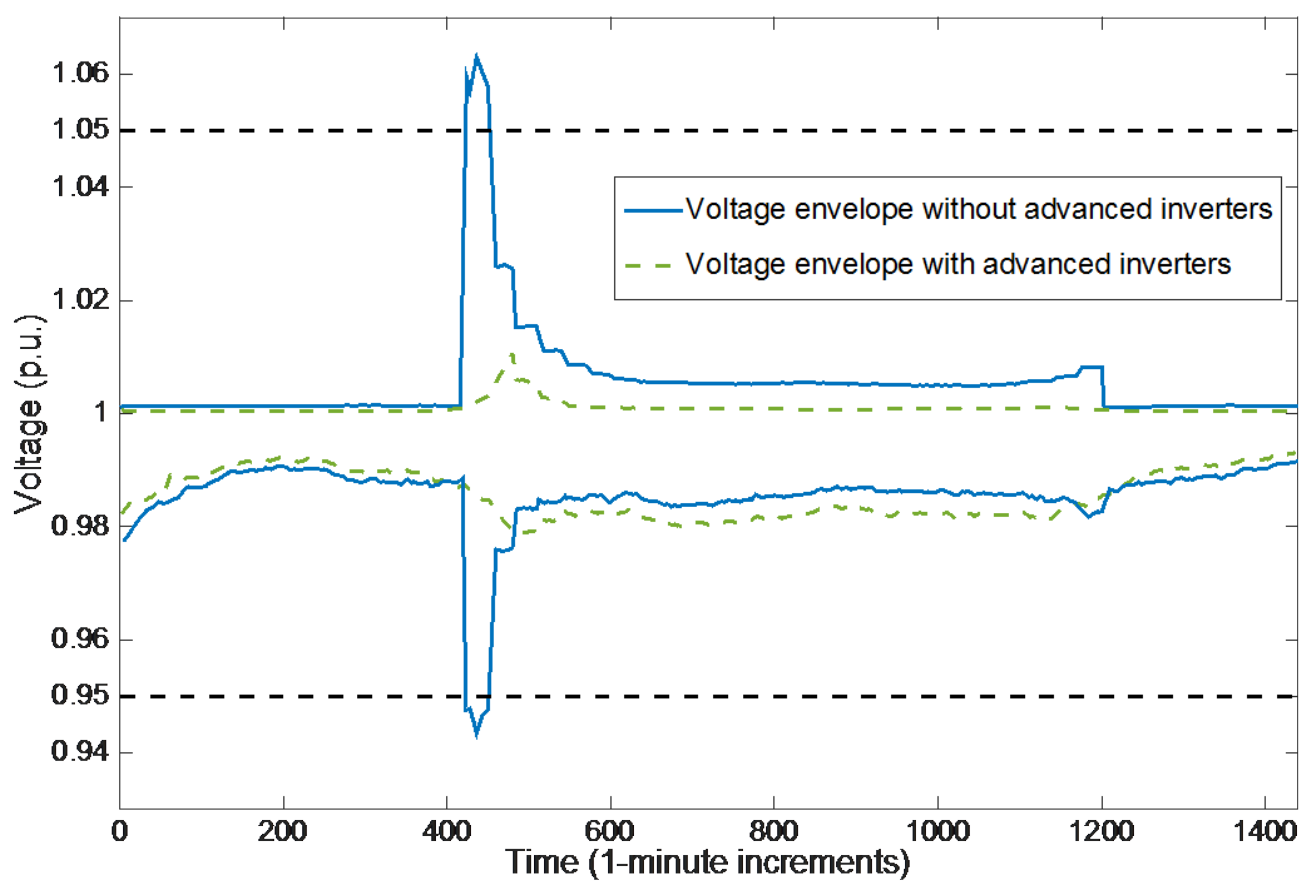

Figure 11. Transmission-level bus voltage magnitudes with and without advanced inverter functionality

\section{Subtask 3.3 - Explore impact of ISO visibility of DGPV on bulk reserves}

In order to examine the impact of DGPV variability, a number of different scenarios were designed. All used the SMUD-like integrated transmission-distribution test system described in subtask 3.1.Three different types of solar power visibility were considered: no visibility for DGPV, persistence forecasts, and full visibility. Each of these scenarios was run for different solar penetration rates and inverter power factors, with the full set of scenarios and results described in Table $\mathrm{V}$ below.

Table V. Scenario Results

\begin{tabular}{|c|c|c|c|c|c|}
\hline $\begin{array}{c}\text { Solar } \\
\text { Penetration } \\
\text { (energy) }\end{array}$ & $\begin{array}{c}\text { Visibility } \\
\text { (Forecast) }\end{array}$ & $\begin{array}{c}\text { Production } \\
\text { Cost } \\
\mathbf{\$ 1 0 0 0} / \text { day }\end{array}$ & $\begin{array}{c}\text { CPS2 } \\
\text { Violations }\end{array}$ & AACEE & $\begin{array}{c}\text { ACE Std. } \\
\text { Dev. }\end{array}$ \\
\hline $9 \%$ & none & \multicolumn{2}{|c|}{ Infeasible RTSCED at 10am simulation time } \\
\hline $9 \%$ & persistence & 7,012 & - & - & - \\
\hline $9 \%$ & perfect & 5,636 & $-25 \%$ & $-7 \%$ & $-4 \%$ \\
\hline $14 \%$ & none & 6,833 & - & - & - \\
\hline $14 \%$ & persistence & 6,558 & $-10 \%$ & $-2 \%$ & $-1 \%$ \\
\hline $14 \%$ & perfect & 5,654 & $-22 \%$ & $-23 \%$ & $-13 \%$ \\
\hline
\end{tabular}

When comparing the different visibility scenarios, there is a clear trend that additional visibility reduces overall production costs. In the $14 \%$ solar penetration rate scenarios adding persistence 
forecasts reduces production costs by $4 \%$, while having full information reduces the costs by $17 \%$. These cost reductions are due to the decreased dispatch costs necessary to deal with the inherent uncertainty of distributed PV. In the same cases CPS2 violations are reduced by $10 \%$ and $21 \%$, respectively, showing the increased reliability from additional visibility into distributed PV production.

Natural gas generation from combustion turbines (CTs) and combined cycle facilities (CCs) are dispatched more in the no-visibility case to allow the total generation to follow the load, since the technologies, particularly CTs, have shorter start-up shut-down time. However, the increase in CT dispatch leads to an increase in system operation cost, because they are less efficient and burn more fuel.

In the same cases CPS2 violations are reduced by $10 \%$ and $21 \%$, respectively, showing the increased reliability from additional visibility into distributed PV production. The increased visibility cases also have a smaller gap between the actual load and the expected net load, which leads to improved reliability metrics, such as CPS2 violations and AACEE.

\section{Task 4 - Demonstration and Dissemination}

\section{Subtask 4.1 - IGMS demonstration}

On September 29, 2015, the IGMS team demonstrated the operation of the IGMS tool via Web conference to the DoE solar-system integration team. This demonstration included a step-by-step description of how the IGMS co-simulation works, an explanation of how data are exchanged, a brief overview of the scenario generation scripts, a live demonstration of the command-linebased tool running on NREL's Peregrine super computer, and a visual demonstration of iPython notebooks and other visualization outputs. Slides from this demonstration were supplied to DOE for reference.

\section{Subtask 4.2 - Dissemination}

The results of this project have been shared with the larger power systems research community through:

- An IEEE Transactions on Smart Grid - special issue on HPC applications journal article (submitted) [17];

- Two conference papers [18], [19], one of which was selected as a Best Paper at the IEEE PES General Meeting 2015;

- An IEEE Electrification Magazine article [20] to appear in early 2016;

- A panel session on HPC applications for planning organized by the PI for the IEEE PES General Meeting 2015 (Denver); and

- Multiple presentations [21]-[23].

Details of these publications and other related products are discussed in the Inventions, Patents, Publications, and Other Results section of this report. 


\section{Significant Accomplishments and Conclusions}

This project demonstrated, for the first time, large-scale integration of hundreds of full-scale (thousands of nodes each) distribution feeders in co-simulation with full resolution transmission and wholesale markets. This represents over 1 million power flow nodes and over 600,000 customers modeled with physics-based end-use models. This capability, along with supporting tools for data management, poses IGMS for follow-on work at even larger scales in partnership with utilities and other interested parties.

As with the development of any large-scale co-simulation platform, challenges and roadblocks were encountered during the development of IGMS. In addition to the accomplishments outlined by the project milestones, the tool was also greatly improved as a result of some of these roadblocks, discussed below.

\section{Accomplishment: Full-Scale Integrated Transmission + Distribution Runs}

The IGMS co-simulation framework was designed to resemble the hierarchical structure of a power system. A transmission-level model connects to a larger number of distribution systems, which are run in parallel. Each transmission (or sub-transmission) load bus is assigned to a load aggregator, which in turn calls that bus's instance of bus.py [18] in order to manage one or more distribution feeders, which are connected at their respective substation. With this architecture, IGMS can utilize the Message Passing Interface (MPI), which allows for a highly scalable, parallel computing solution in HPC environments. A block diagram detailing the architecture of IGMS can be seen in Figure 12.

The test cases that were simulated using IGMS were a three-bus test case, the IEEE-14 bus test case, the IEEE-118 bus test case, and the largest, a SMUD-like transmission case. A total of 13 scenarios based on SMUD topology, 2010 levels of load and generator build-out, and load and renewable resource time series data from 2006 were created to simulate the SMUD-like case, which contains over 250 transmission-level buses and 950 distribution feeders. Each of the distribution feeders had hundreds to thousands of electrical nodes and physics-based models for buildings and DGPV systems. The simulation of an electrical system this large was a big accomplishment for this project. The results of simulations run for the SMUD-like case are detailed further in the Project Results and Discussion section above. 


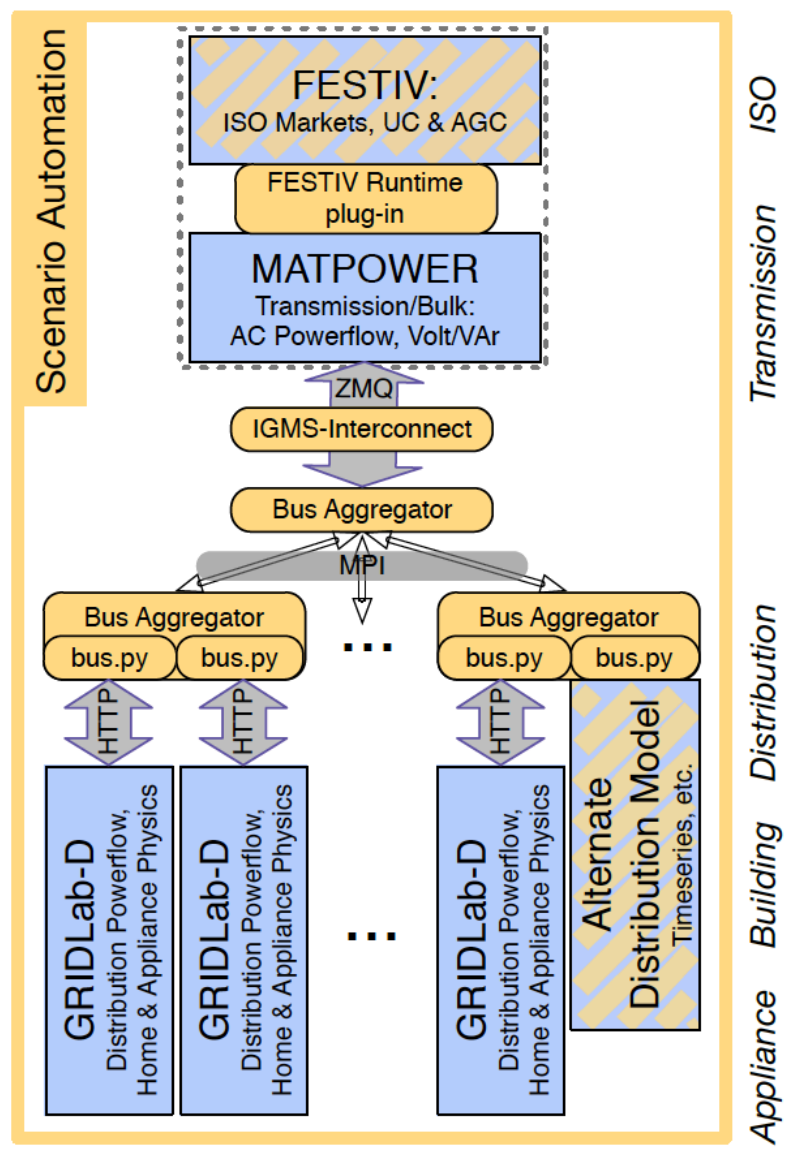

Figure 12. IGMS Architecture

\section{Accomplishment: Automated Scenario Creation}

With hundreds upon thousands of distribution feeder models required for an IGMS simulation, scenario construction by hand would be inefficient and impractical. As a result, an objectoriented scenario creation framework was created in Python. The layout of the ScenarioCreator hierarchy is seen in Figure 13.

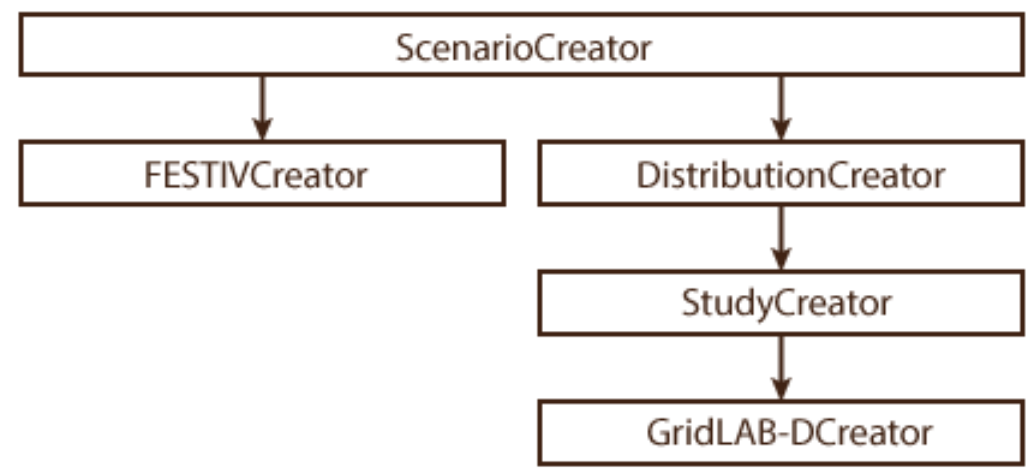

Figure 13. The scenario creation hierarchy 
The DistributionCreator class handles the feeder assignment to transmission buses in order to match peak loads. The StudyCreator class assigns high-level parameters to the feeders, such as DER penetrations. StudyCreator supports Latin Hypercube Sampling (LHS) to randomize parameter value selection. Finally, the GridLAB-DCreator populates bare feeders with building and DER models. These population scripts are discussed further below under the "Feeder Population Script Improvement" section.

The last piece of the ScenarioCreator hierarchy, the FESTIVCreator, instantiates the transmission system models. These models are typically developed externally and then imported into the IGMS scenarios. Some high-level parameters specified at the ScenarioCreator level are passed down into the FESTIV model (simulation time step, start time, and end time, for example). Scenario-wide parameters such as these are coordinated with the distribution models.

\section{Accomplishment: Tools for Efficient Debugging}

In order to make the debugging of IGMS easier, "dummy" versions of each individual tool (FESTIV, IGMS, GridLAB-D) were developed. These dummy versions provided a strippeddown implementation of their respective tools to not only simplify the debugging process, but also to speed up simulation time by reducing the initial start-up time and run-time of the integrated IGMS tool. The FESTIV dummy tool, for example, returns constant electricity prices for each transmission-level bus and constant generation values instead of simulating the entire day-ahead and real-time energy markets.

\section{Accomplishment: Feeder Population Script Improvement}

The Open Modeling Framework (OMF) [24] feeder population scripts were used as a basis for the IGMS scenario creation framework, which allowed for the automation of the population of feeder models with realistic buildings, PV panels, and inverters. However, the original OMF code required manual feeder cleanup to reduce simulation warnings, and to achieve more realistic populations of DGPV and buildings. To overcome these challenges, we made a wide array of improvements to the feeder population scripts.

This effort started by conducting a series of annual simulations and extracted data on a perbuilding basis. The original feeder population scripts choose one building type (residential, strip mall, big box, office, etc.) per distribution node. The difficulty lies in the fact that the building objects are added until the peak load of the populated model was a close match to the peak load of the base model; however, with the commercial building types in particular, there is a wide spread in peak power, as seen in Figure 14. This made it difficult to match the feeder-level peak loads between the base models and the populated models. 


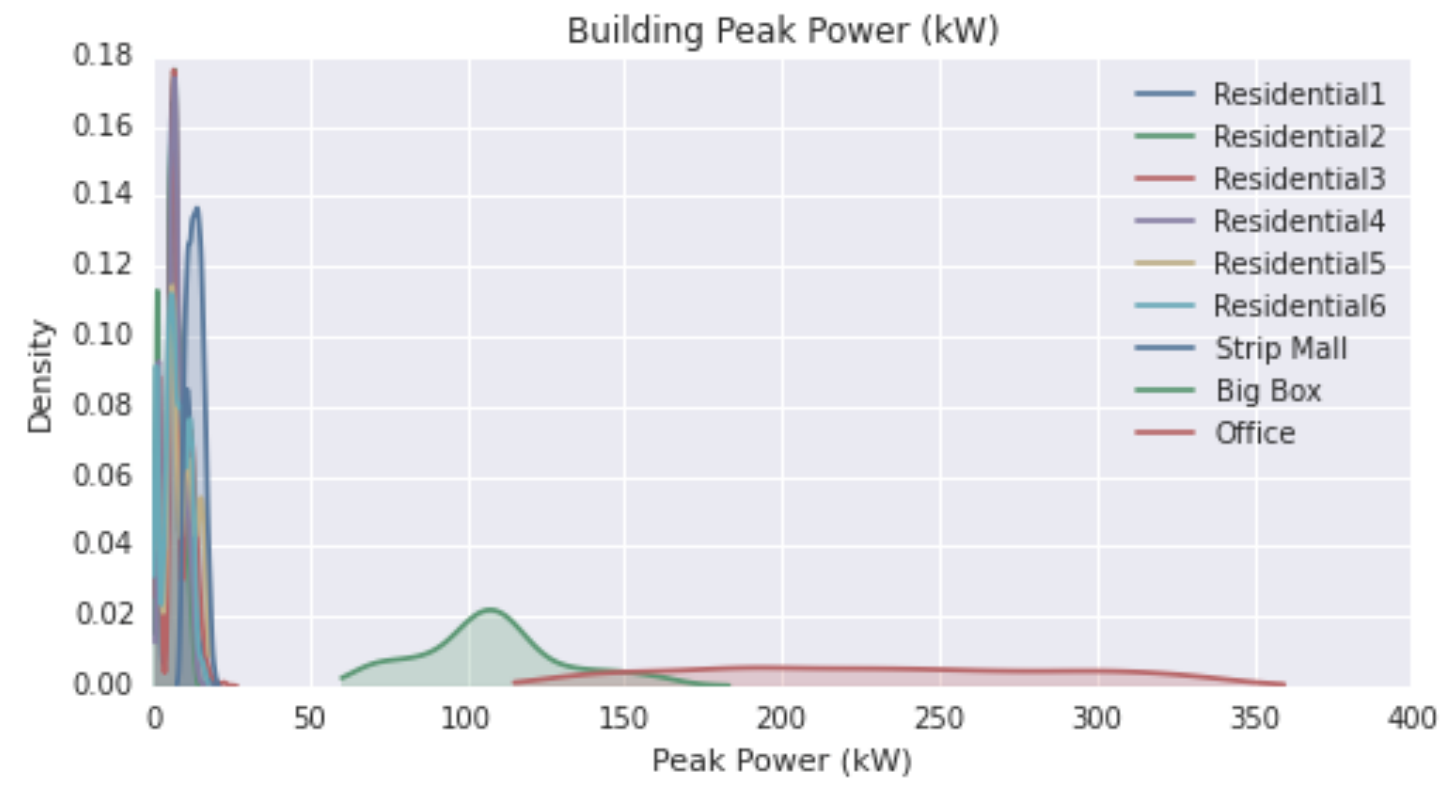

Figure 14. Building peak power (kW) for various building types in a particular climate zone

Thus, the population scripts were reworked to more intelligently determine the number of buildings that were assigned to a feeder. By reforming the distributions of peak power for each of the building types and specifying a building floor area, climate, and building-type-specific peak power intensity, and by assuming that the PV should be sized to fully meet the expected annual load, the accuracy of the method was improved. The relative tightness of the distributions of the normalized distributions is seen in Figure 15. The improved feeder population script has been released to the open-source community under the name glmgen [25].

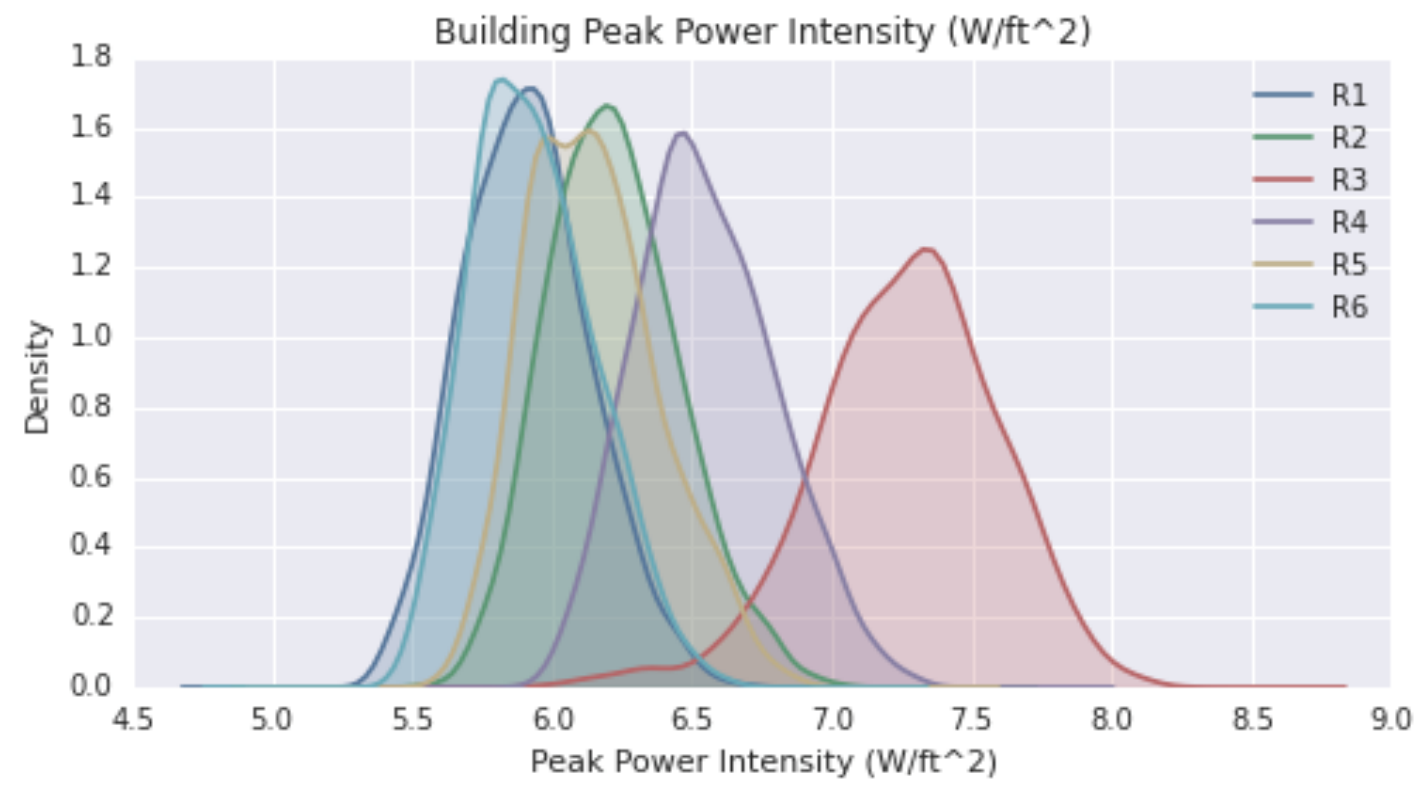

Figure 15. Office building peak power intensity, normalized for a tighter distribution 


\section{Accomplishment: Parallelization Efforts and Improved GridLAB-D Interfacing}

Another issue the IGMS team encountered was communication limitations from GridLAB-D. GridLAB-D's ability to run as an HTTP (web) server was chosen because of its flexibility and robustness among options for remote interactions with GridLAB-D. In Figure 16, a single GridLAB-D timestep is shown broken up into three periods: communication to, processing, and communication from.

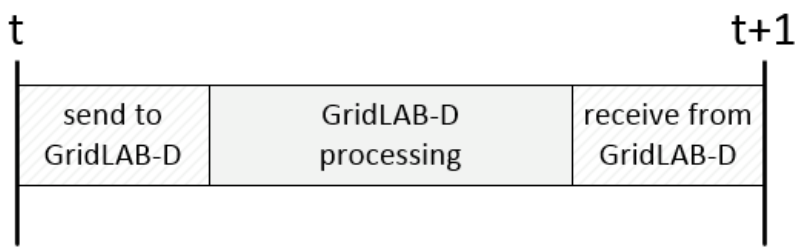

Figure 16. A single GridLAB-D timestep

However, the length of communication to and from GridLAB-D is dependent on the speed of the communication protocol and the amount of data exchanged. The GridLAB-D processing step is a function of the size of the feeder being simulated. The initial implementation of GridLAB-D runs in IGMS is shown in Figure 17 for nodes $1 \ldots \mathrm{N}$.

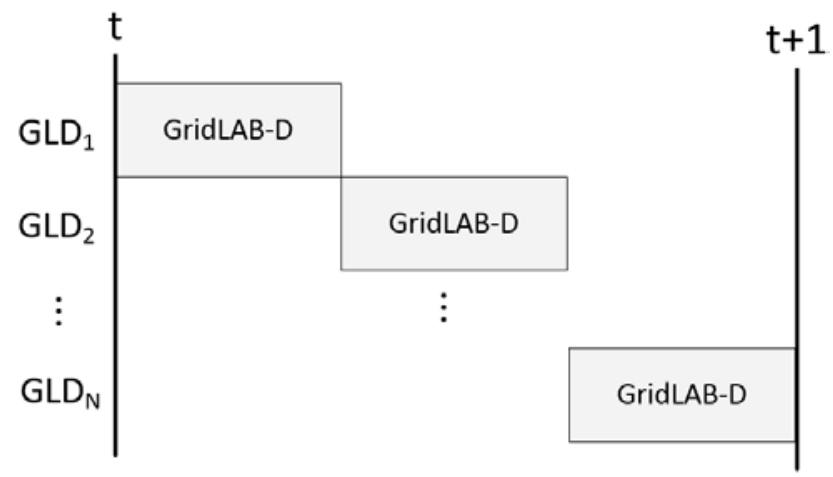

Figure 17. Initial IGMS parallelization of GridLAB-D for $\mathbf{N}$ instances on each rank

On a single MPI rank, each GridLAB-D instance runs to completion sequentially. Parallelization was only achieved through multiple ranks. In the current IGMS architecture, this parallelization was considerably improved by overlapping the processing of the GridLAB-D instances with some of the communication time. This is shown in Figure 18.

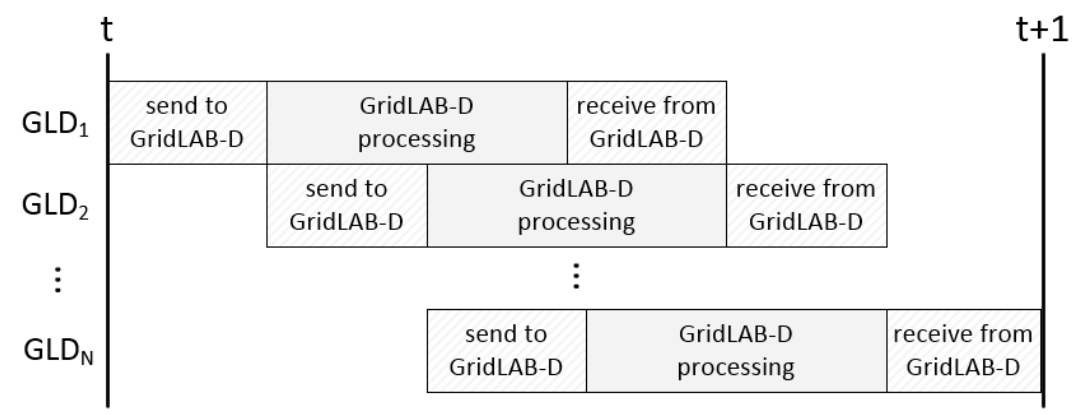

Figure 18. GridLAB-D improved parallelization on each rank by using overlapping computation 
Table VI shows the improvement in computation time for the IEEE-118 bus test system [26] with $100 \%$ of the load simulated over 717 GridLAB-D taxonomy feeders [16] with randomized loads.

Table VI. Improved performance with parallelization of GridLAB-D on the IEEE 118 bus test system

\begin{tabular}{|l|l|l|l|}
\hline Nodes & Old & New & x Speedup \\
\hline 14 & 66413 & 15169 & 4.4 \\
\hline 34 & 36333 & 13565 & 2.7 \\
\hline
\end{tabular}

Further improvements should be possibly by completely parallelizing the calls to GridLAB-D by initializing the "Send to GridLAB-D" stage for all feeders simultaneously for each bus.py instance. This effort is left for future development

\section{Challenge Overcome: Performance Issues and Balancing Memory Across Ranks}

When the number of feeders assigned to each transmission bus is roughly equal, each rank is assigned similar levels of buses and thus feeders. However, in practice, each transmission bus is assigned different numbers of feeders, and this results in poor load balancing across ranks. This does not only affect computational performance, but it also can impact the memory usage, especially in non-shared-memory HPC systems. A GridLAB-D (v3.0) full-scale feeder instance requires approximately $1 \mathrm{~GB}$ of RAM to run, and most of the HPC compute nodes that were used in IGMS simulations have about $32 \mathrm{~GB}$ each, creating an upper limit on the number of feeders that can be simulated per node. Using more memory than available causes the node to crash, ending the entire computation.

Sequentially or randomly assigning transmission buses to ranks, and thus compute nodes, did not result in a uniform distribution of feeders. To overcome this challenge, we implemented a priority queue-based allocation that iteratively assigns the next bus with the largest number of feeders to the rank that currently has the lowest number of feeders. This results in an allocation of feeders that is nearly uniform, and is limited only by the inability to partition buses with large numbers of feeders.

\section{Conclusions}

The simulation of large power systems with hundreds to thousands of buses from the ISO level to the household appliance level was the biggest accomplishment of this project, because it allowed for the exploration of research questions that may not have been possible to fully address before. There were roadblocks and challenges encountered, but in many cases, overcoming these and implementing creative solutions to the encountered problems resulted in dramatic efficiency increases and insights into simulation robustness. The posed research questions in the milestone were answered successfully, and it seems promising that by using this tool, even larger and more complex analyses that combine transmission and distribution simulation are now possible for high-penetration DGPV, other DERs, and beyond. 


\section{Inventions, Patents, Publications, and Other Results}

There were multiple publications, presentations, and other outcomes that resulted from this project:

- Our journal article was submitted after being encouraged based on an extended abstract: B. Palmintier, E. Hale, T. Hansen, W. Jones, D. Biagioni, H. Sorensen, and B.M. Hodge, "IGMS: An Integrated ISO-to-Appliance Scale Grid Modeling System," IEEE Transactions on Smart Grid, no. Special Issue on High Performance Computing (HPC) Applications for a More Resilient and Efficient Power Grid, 2016 (In review).

- Our paper on a piece of IGMS called bus.py was selected as a Best Paper at the IEEE PES General Meeting 2015: T. M. Hansen, B. Palmintier, S. Suryanarayanan, A. Maciejewski, and H. J. Siegel, "Bus.py: A GridLAB-D Communication Interface for Smart Distribution Grid Simulations," in Proceedings of the 2015 IEEE PES General Meeting, Denver, CO, July 2015.

- IGMS will be featured as part of a magazine article on co-simulation approaches for smart grid simulations: T. M. Hansen, R. Kadavil, B. Palmintier, S. Suryanarayanan, A. Maciejewski, H. J. Siegel, E. K. P. Chong, and E. Hale, "Enabling Smart Grid CoSimulation Studies," IEEE Electrification, 2016.

- We lead a panel session for the IEEE PES General Meeting 2015 entitled "HPC in Power Systems Planning," with industry, academia, PNNL, LLNL participation.

- We presented during our session at the IEEE PES General Meeting 2015: B. Palmintier, "The Integrated Grid Modeling System (IGMS) for Combined Transmission and Distribution Simulation," presented at the Power and Energy Society General Meeting, Denver, CO, 29-Jul-2015.

- Based on IEEE PES General Meeting exposure, we gave an invited presentation at EPRI's advisory meeting: B. Palmintier, "Transmission and Distribution Co-simulation using HPC," presented at the EPRI Grid Ops and Planning Advisory Meeting, Baltimore, MD, 05-Oct-2015.

- We submitted an paper to the $19^{\text {th }}$ Power Systems Computation Conference (PSCC) to be held in Genoa, Italy, June, 2016: B. Palmintier, E. Hale, B.-M. Hodge, K. Baker, and T. Hansen, "Experiences integrating transmission and distribution simulations for DERs with the Integrated Grid Modeling System (IGMS)," in Proceedings of the 19th Power Systems Computation Conference (PSCC'16), Genoa, Italy, June 2016. (In review)

- We presented at the AIChE Annual Meeting: B.-M. Hodge, E. Hale, B. Palmintier, J. Wei, J. Giraldez, W. Jones, D. Biagioni, and R. Mossop, "Cyber-Physical-Energy Systems Testbed: A Distributed Solar Power Case Study," presented at the 2014 AIChE Annual Meeting, Atlanta, GA, 19-Nov-2014.

- In addition multiple sub-components developed under IGMS were released as opensource software: E. Hale, T. M. Hansen, and B. Palmintier, glmgen: Python scripting for GridLAB-D input files. 2014. And T. M. Hansen, B. Palmintier, and E. Hale, buspy. 2015. Both are available at github.com. 


\section{Path Forward}

This project established a strong foundation for future integrated market-transmissiondistribution-end-use modeling and simulation. Looking forward, there are a wide range of applications and future research directions enabled by this capability, including in particular:

- Continuing to explore the operational impacts of high-penetration DGPV on system-wide operations;

- Exploring the impacts of system-wide operations on DGPV;

- Accurate simulation of price-responsive demand considering physical limits of end uses;

- Further developing the IGMS tool, including the use of commercial tools within the modular co-simulation framework; and

- Working with utility partners to apply IGMS to real-world systems and data.

Currently there are no pending or accepted projects to directly address these directions. However, there are multiple upcoming projects that will incorporate the integrated transmission/distribution analysis that IGMS can provide in their research. 


\section{References}

[1] E. Ela and M. O'Malley, "Studying the Variability and Uncertainty Impacts of Variable Generation at Multiple Timescales," IEEE Trans. Power Syst., vol. 27, no. 3, pp. 1324-1333, Aug. 2012.

[2] R. D. Zimmerman, C. E. Murillo-Sánchez, and R. J. Thomas, "MATPOWER: Steady-State Operations, Planning, and Analysis Tools for Power Systems Research and Education," IEEE Trans. Power Syst., vol. 26, no. 1, pp. 12-19, Feb. 2011.

[3] D. P. Chassin, J. C. Fuller, and N. Djilali, "GridLAB-D: An Agent-Based Simulation Framework for Smart Grids," J. Appl. Math., vol. 2014, pp. 1-12, 2014.

[4] P. Evans and New Power Technologies, "Regional Transmission and Distribution Network Impacts Assessment for Wholesale Photovoltaic Generation," California Energy Commission, CEC -200- 2014 - 004, Aug. 2014.

[5] D. Aliprantis, S. Penick, L. Tesfatsion, and H. Zhao, "Integrated retail and wholesale power system operation with smart-grid functionality," in 2010 IEEE Power and Energy Society General Meeting, 2010, pp. 1-8.

[6] K. Anderson, J. Du, A. Narayan, and A. El Gamal, "GridSpice: A distributed simulation platform for the smart grid," in 2013 Workshop on Modeling and Simulation of Cyber-Physical Energy Systems (MSCPES), 2013, pp. 1-5.

[7] J. Daily, J. Fuller, S. Ciraci, A. Fisher, L. Marinovic, and K. Agarwal, "FNCS: Framework for Network Co-Simulation," Richland, WA, 22-Jan-2014.

[8] F. Marten, L. Löwer, J.-C. Töbermann, and M. Braun, "Optimizing the Reactive Power Balance between a Distribution and Transmission Grid through Iteratively Updated Grid Equivalent," in Proceedings of the 18th Power Systems Computation Conference (PSCC'14), Wroclaw, Poland, 2014.

[9] R. Roche, S. Natarajan, A. Bhattacharyya, and S. Suryanarayanan, "A Framework for Co-simulation of Al Tools with Power Systems Analysis Software," in 2012 23rd International Workshop on Database and Expert Systems Applications (DEXA), 2012, pp. 350-354.

[10] J. Gomez-Gualdron and M. Velez-Reyes, "Simulating a multi-agent based selfreconfigurable electric power distribution system," presented at the IEEE Workshops on Computers in Power Electronics (COMPEL'06), 2006, pp. 1-7.

[11] T. Godfrey, S. Mullen, R. Dugan, C. Rodine, D. Griffith, and N. Golmie, "Modeling smart grid applications with co-simulation," presented at the First IEEE International Conference on Smart Grid Communications (SmartGrid-Comm), 2010, pp. 291-296.

[12] M. Lévesque, D. Q. Xu, G. Joós, and M. Maier, "Communications and power distribution network co-simulation for multidisciplinary smart grid experimentations," in Proceedings of the 45th Annual Simulation Symposium (ANSS '12), 2012, pp. 27.

[13] A. Awad, P. Bazan, and R. German, "SGsim: A simulation framework for smart grid applications," presented at the 2014 IEEE International Energy Conference (ENERGYCON), Dubrovnik, Croatia, 2014.

[14] H. Lin, S. Sambamoorthy, S. Shukla, J. Thorp, and L. Mili, "Power system and communication network co-simulation for smart grid applications," presented at the IEEE PES Innovative Smart Grid Technologies (ISGT), 2011, pp. 1-6. 
[15] B. M. Kelley, P. Top, S. G. Smith, C. S. Woodward, and L. Min, "A federated simulation toolkit for electric power grid and communication network co-simulation," in 2015 Workshop on Modeling and Simulation of Cyber-Physical Energy Systems (MSCPES), 2015, pp. 1-6.

[16] K. P. Schneider, Y. Chen, D. Engle, and D. Chassin, "Taxonomy of North American radial distribution feeders," presented at the Power \& Energy Society General Meeting 2009, Calgary, AB, 2009.

[17] B. Palmintier, E. Hale, T. Hansen, W. Jones, D. Biagioni, H. Sorensen, and B.-M. Hodge, "IGMS: An Integrated ISO-to-Appliance Scale Grid Modeling System," IEEE Trans. Smart Grid, no. Special Issue on High Performance Computing (HPC) Applications for a More Resilient and Efficient Power Grid, In Review 2015.

[18] T. M. Hansen, B. Palmintier, S. Suryanarayanan, A. Maciejewski, and H. J. Siegel, "Bus.py: A GridLAB-D Communication Interface for Smart Distribution Grid Simulations," presented at the IEEE PES General Meeting 2015, Denver, CO, 2015.

[19] B. Palmintier, E. Hale, B.-M. Hodge, K. Baker, and T. Hansen, "Experiences integrating transmission and distribution simulations for DERs with the Integrated Grid Modeling System (IGMS)," in Proceedings of the 19th Power Systems Computation Conference (PSCC'16), Genoa, Italy, 2016.

[20] T. M. Hansen, R. Kadavil, B. Palmintier, S. Suryanarayanan, A. Maciejewski, H. J. Siegel, E. K. P. Chong, and E. Hale, "Enabling Smart Grid Co-Simulation Studies," IEEE Electrification, 2016.

[21] B. Palmintier, "The Integrated Grid Modeling System (IGMS) for Combined Transmission and Distribution Simulation," presented at the Power and Energy Society General Meeting, Denver, CO, 29-Jul-2015.

[22] B. Palmintier, "Transmission and Distribution Co-simulation using HPC," presented at the EPRI Grid Ops and Planning Advisory Meeting, Baltimore, MD, 05-Oct-2015.

[23] B.-M. Hodge, E. Hale, B. Palmintier, J. Wei, J. Giraldez, W. Jones, D. Biagioni, and R. Mossop, "Cyber-Physical-Energy Systems Testbed: A Distributed Solar Power Case Study," presented at the 2014 AIChE Annual Meeting, Atlanta, GA, 19-Nov2014.

[24] D. Pinney, C. Miller, and T. Lovas, "Costs and Benefits of Conservation Voltage Reduction: CVR Warrants Careful Examination, Initial Findings," National Rural Electric Cooperative Association (NRECA) Cooperative Research Network (CRN), Arlington, VA, DE-OE0000222, Nov. 2013.

[25] E. Hale, T. M. Hansen, and B. Palmintier, glmgen: Python scripting for GridLAB-D input files. 2014.

[26] W. H. Kersting, "Radial distribution test feeders," in IEEE Power Engineering Society Winter Meeting, 2001, 2001, vol. 2, pp. 908 -912 vol.2. 


\section{Appendix-Milestone Status Summary}

\begin{tabular}{|c|c|c|c|c|c|}
\hline & Metric Definition & Success Value & Measured Value & Assessment Method & \\
\hline 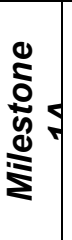 & $\begin{array}{l}\text { Output processing } \\
\text { accurately captures } \\
\text { distribution simulation } \\
\mathrm{P}, \mathrm{Q} \text {, and V results in } \\
\text { database and } \\
\text { graphics }\end{array}$ & $\begin{array}{l}\text { All sampled comparisons of database } \\
\text { and graphical data match raw CSV } \\
\text { and other outputs within round-off } \\
\text { error }\end{array}$ & $\begin{array}{l}\text { All data matches the graphics } \\
\text { and text summaries }\end{array}$ & $\begin{array}{l}\text { Randomly sampled } \\
\text { timeseries comparision } \\
\text { and manual graphics } \\
\text { checks }\end{array}$ & $\begin{array}{l}100 \% \\
\text { complete } \\
\text { Milestone } \\
\text { met }\end{array}$ \\
\hline 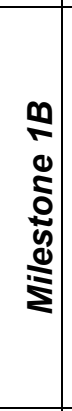 & $\begin{array}{l}\text { Semi-automated } \\
\text { conversion of system } \\
\text { data reproduces } \\
\text { powerflow } P, Q \text {, and } \\
\text { V results }\end{array}$ & $\begin{array}{l}\text { RMS error }<5 \% \text { for one }(1) \\
\text { transmission region and two (2) } \\
\text { distribution feeders }\end{array}$ & $\begin{array}{l}\text { Transmission: } \\
|\Delta \mathrm{P}|_{\text {mean }}=2.6 \% \\
\Delta \mathrm{P}_{\mathrm{rms}}=4.9 \% \\
\mid \Delta \text { Cost } \mid=0.3 \% \\
\mathrm{Q} \& V \text { not computed by Plexos } \\
\text { Distribution: } \\
|\Delta \mathrm{P}|=1 \% \\
|\Delta \mathrm{Q}|=1 \% \\
|\Delta \mathrm{V}| \approx 4 \%\end{array}$ & $\begin{array}{l}\text { Timeseries comparison } \\
\text { of native tool to IGMS } \\
\text { tool results } \\
\text { Distribution: no time } \\
\text { series in original tool, } \\
\text { so snapshot used }\end{array}$ & $\begin{array}{l}100 \% \\
\text { complete } \\
\text { Milestone } \\
\text { met }\end{array}$ \\
\hline 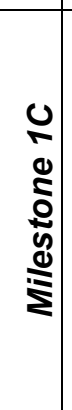 & $\begin{array}{l}\text { DGPV scenario } \\
\text { generator able to } \\
\text { automatically create } \\
\text { penetration scenarios }\end{array}$ & $\begin{array}{l}\text { Original: } \\
\text { Fotal capacity of installed DGPV } \\
\text { matches target percentage within } \\
\text { average DGPV system capacity. } \\
\text { Revised: For the bulk power level, } \\
\text { energy based penetrations (such as } \\
\text { for RPS) are of more interest, so } \\
\text { modified to try to match annual } \\
\text { energy basis. }\end{array}$ & $\begin{array}{l}\text { Target: } 2-3 \%, 8-10 \%, 14-18 \% \\
\text { solar penetration on an annual } \\
\text { energy basis, Actual: } 2,9,14 \% \\
\text { (Updated) }\end{array}$ & $\begin{array}{l}\text { Original: Compare sum } \\
\text { of DGPV nameplate } \\
\text { divided by peak load to } \\
\text { target percent. } \\
\text { Compare sum of DGPV } \\
\text { energy to target } \\
\text { percent. }\end{array}$ & $\begin{array}{l}100 \% \\
\text { complete } \\
\text { Milestone } \\
\text { met }\end{array}$ \\
\hline 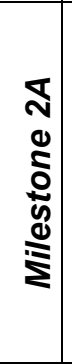 & $\begin{array}{l}\text { Characterize the } \\
\text { impact of integrated } \\
\text { transmission- } \\
\text { distribution modeling } \\
\text { as implemented in } \\
\text { IGMS }\end{array}$ & $\begin{array}{l}\mathrm{P}, \mathrm{Q}, \mathrm{V} \text {, and/or LMP differences }>5 \% \\
\text { of the observed range of variations } \\
\text { Measured as mean relative deviation }\end{array}$ & $\begin{array}{l}\text { Using standard data... } \\
\text { GridLAB-IGMS: }|\Delta P| \approx 13.0 \% \\
|\Delta Q| \approx 16.3 \% \\
|\Delta V| \approx 1.23 \% \\
\text { FESTIV-IGMS: } \\
|\Delta P| \approx 15.8 \% \\
|\Delta Q| \approx 76.7 \% \\
|\Delta V| \approx 0.043 \%\end{array}$ & $\begin{array}{l}\text { Timeseries analysis } \\
\text { comparing "separate- } \\
\text { standard" to } \\
\text { "integrated" }\end{array}$ & $\begin{array}{l}100 \% \\
\text { Complete } \\
\text { Milestone } \\
\text { Met: } \\
\text { differences } \\
\text { are notably } \\
\text { larger than } \\
\text { for M2B }\end{array}$ \\
\hline
\end{tabular}




\begin{tabular}{|c|c|c|c|c|c|}
\hline & Metric Definition & Success Value & Measured Value & Assessment Method & Status \\
\hline 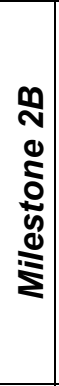 & $\begin{array}{l}\text { Verify the } \\
\text { interconnection of } \\
\text { sub-tools in IGMS }\end{array}$ & $\begin{array}{l}\mathrm{P}, \mathrm{Q}, \mathrm{V}, \text { and/or } \mathrm{LMP} \text { differences }<5 \% \\
\text { of the observed range of variations } \\
\text { Measured as mean relative deviation }\end{array}$ & $\begin{array}{l}\text { Using IGMS outputs as input } \\
\text { data... IGMS-GridLAB: }|\Delta P| \approx \\
0.59 \% \\
|\Delta \mathrm{Q}| \approx 11.1 \% \\
|\Delta \mathrm{V}| \approx 0.00 \% \\
\mid \mathrm{GMS}-\mathrm{FESTIV:} \\
|\Delta \mathrm{P}| \approx 11.5 \% \\
|\Delta \mathrm{Q}| \approx 22.0 \% \\
|\Delta \mathrm{V}| \approx 0.053 \%\end{array}$ & $\begin{array}{l}\text { Timeseries analysis } \\
\text { comparing "separate- } \\
\text { igms" to "integrated" }\end{array}$ & $\begin{array}{l}100 \% \\
\text { Complete } \\
\text { Milestone } \\
\text { Met: } \\
\text { Differences } \\
\text { generally } \\
\text { well } \\
\text { contained. }\end{array}$ \\
\hline 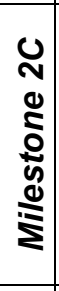 & $\begin{array}{l}\text { Understand how } \\
\text { IGMS simulation } \\
\text { performance scales } \\
\text { with number of } \\
\text { distribution feeders } \\
\text { and number of } \\
\text { computation nodes. }\end{array}$ & $\begin{array}{l}\text { Representation of runtime covering } \\
\text { three (3) or more orders of magnitude } \\
\text { in numbers of simulated feeders (e.g. } \\
1-1000)\end{array}$ & $\begin{array}{l}\text { Run results for } 1-743 \text { feeders } \\
\text { ( } 2.88 \text { orders of magnitude) } \\
\text { were analyzed. } \\
\text { Later: improved speed by } 3+ \\
\text { times }\end{array}$ & $\begin{array}{l}\text { Store and compare } \\
\text { simulation run time } \\
\text { (wallclock) }\end{array}$ & $\begin{array}{l}100 \% \\
\text { complete } \\
\text { Milestone } \\
\text { met }\end{array}$ \\
\hline 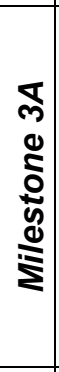 & $\begin{array}{l}\text { Ready to conduct } \\
\text { research question } \\
\text { analysis. }\end{array}$ & $\begin{array}{l}\text { Scenario parameters defined } \\
\text { and baseline simulations run. } \\
\text { Baseline set of energy from DGPV } \\
\text { within } 5 \% \text { of target scenario values. }\end{array}$ & $\begin{array}{l}\text { 30total: } 3 \text { PV levels } \\
\text { x } 7 \text { scenarios } \\
+\approx 9 \text { sensitivities } \\
\text { FESTIV and GridLAB runs of } \\
\text { SMUD system complete } \\
\text { Target: } 10 \% \text { energy } \\
\text { Actual: } 14 \% \text { energy }\end{array}$ & $\begin{array}{l}\text { Summary statistic } \\
\text { comparison }\end{array}$ & $\begin{array}{l}100 \% \\
\text { complete } \\
\text { Milestone } \\
\text { met }\end{array}$ \\
\hline 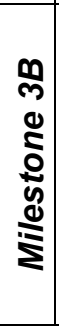 & $\begin{array}{l}\text { Understand the } \\
\text { impact of advanced } \\
\text { inverter based DGPV }\end{array}$ & $\begin{array}{l}\text { For each PV penetration scenario and } \\
\text { improved DGPV visibility options, } \\
\text { determine difference in amount of } \\
\text { reserves deployed and impact of ACE } \\
\text { and CPS2 from the baseline case of } \\
\text { using net load visibility for the ISO. } \\
\text { Of reactive power flow and } \\
\text { transmission voltages. }\end{array}$ & $\begin{array}{l}\text { Transmission level reactive } \\
\text { power requirements decreased } \\
\text { increase slightly and distribution } \\
\text { power factors shift away from } \\
\text { nominal with DGPV reactive } \\
\text { power injection absorption at } \\
\mathrm{PF}=0.95 \text { to mitigate local } \\
\text { voltage concerns. (Updated) }\end{array}$ & $\begin{array}{l}\text { Timeseries analysis } \\
\text { and Summary statistic } \\
\text { comparison }\end{array}$ & $\begin{array}{l}100 \% \\
\text { complete } \\
\text { Milestone } \\
\text { met }\end{array}$ \\
\hline
\end{tabular}




\begin{tabular}{|c|c|c|c|c|c|}
\hline & Metric Definition & Success Value & Measured Value & Assessment Method & Status \\
\hline 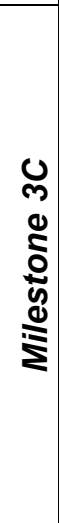 & $\begin{array}{l}\text { Understand the } \\
\text { impact of using the } \\
\text { IGMS tool in terms of } \\
\text { improved estimation } \\
\text { ef key metrics from } \\
\text { the baseline of net } \\
\text { load forecast } \\
\text { (demand + solar } \\
\text { power production) } \\
\text { ISO visibility of DGPV } \\
\text { on system operations } \\
\text { and reserve } \\
\text { deployment. }\end{array}$ & $\begin{array}{l}\text { For each PV penetration scenario and } \\
\text { improved DGPV visibility options, } \\
\text { determine difference in amount of } \\
\text { reserves deployed and impact of ACE } \\
\text { and CPS2 from the baseline case of } \\
\text { using net load visibility for the ISO. }\end{array}$ & $\begin{array}{l}\text { Increasing visibility of DGPV } \\
\text { degreased operating costs and } \\
\text { reduced the need for reserve } \\
\text { deployments }\end{array}$ & $\begin{array}{l}\text { Timeseries analysis } \\
\text { and Summary statistic } \\
\text { comparison }\end{array}$ & $\begin{array}{l}100 \% \\
\text { complete } \\
\text { Milestone } \\
\text { met }\end{array}$ \\
\hline \multirow{3}{*}{\multicolumn{2}{|c|}{ Final Deliverables }} & $\begin{array}{l}\text { 1. Demonstration of IGMS tool to } \\
\text { project sponsors }\end{array}$ & \multicolumn{2}{|c|}{ NREL-DoE web meeting September 29, 2015} & $\begin{array}{l}100 \% \\
\text { complete } \\
\text { Milestone } \\
\text { met }\end{array}$ \\
\hline & & $\begin{array}{l}\text { 2. Providing a final power point } \\
\text { presentation on the IGMS tool } \\
\text { development, features, description } \\
\text { of step used to apply IGMS to a } \\
\text { specific use case, and the detailed } \\
\text { results of the impact studies }\end{array}$ & \multicolumn{2}{|c|}{ Provided as part of NREL-DoE web meeting. } & $\begin{array}{l}100 \% \\
\text { complete } \\
\text { Milestone } \\
\text { met }\end{array}$ \\
\hline & & $\begin{array}{l}\text { 3. Submitted final report in form of } \\
\text { two publications: one conference } \\
\text { paper (e.g. IEEE PES General } \\
\text { Meeting or PVSC) describing } \\
\text { IGMS, and submission of one } \\
\text { peer-reviewed journal article (e.g } \\
\text { IEEE Transactions in Power } \\
\text { Systems or IEEE Transactions on } \\
\text { Smart Grid-special issue on HPC } \\
\text { applications) summarizing the } \\
\text { research approach and findings }\end{array}$ & \multicolumn{2}{|c|}{$\begin{array}{l}\text { One (1) journal article submitted to IEEE Transactions on } \\
\text { Smart Grid-special issue on HPC applications } \\
\text { Two (2) conference papers: One won best paper award at } \\
\text { the IEEE PES General Meeting } 2015 \text { (Denver), the other } \\
\text { submitted to the Power Systems Computation Conference } \\
\text { (PSCC) for June } 2016 \text {. } \\
\text { Additional presentations as described in the } \\
\text { Inventions, Patents, Publications, and Other Results } \\
\text { section. }\end{array}$} & $\begin{array}{l}100 \% \\
\text { complete } \\
\text { Milestone } \\
\text { met }\end{array}$ \\
\hline
\end{tabular}

